NATIONAL LABORATORY

\title{
Developing Generic Dynamic Models for the 2030 Eastern Interconnection Grid
}

\section{December 2013}

\section{Prepared by}

\section{Gefei Kou}

Stanton W. Hadley

Penn Markham

Yilu Liu






\section{DOCUMENT AVAILABILITY}

Reports produced after January 1, 1996, are generally available free via US Department of Energy (DOE) SciTech Connect.

Website http://www.osti.gov/scitech/

Reports produced before January 1, 1996, may be purchased by members of the public from the following source:

National Technical Information Service

5285 Port Royal Road

Springfield, VA 22161

Telephone 703-605-6000 (1-800-553-6847)

TDD 703-487-4639

Fax 703-605-6900

E-mail info@ntis.gov

Website http://www.ntis.gov/support/ordernowabout.htm

Reports are available to DOE employees, DOE contractors, Energy Technology Data Exchange representatives, and International Nuclear Information System representatives from the following source:

Office of Scientific and Technical Information

PO Box 62

Oak Ridge, TN 37831

Telephone 865-576-8401

Fax 865-576-5728

E-mail reports@osti.gov

Website http://www.osti.gov/contact.html

This report was prepared as an account of work sponsored by an agency of the United States Government. Neither the United States Government nor any agency thereof, nor any of their employees, makes any warranty, express or implied, or assumes any legal liability or responsibility for the accuracy, completeness, or usefulness of any information, apparatus, product, or process disclosed, or represents that its use would not infringe privately owned rights. Reference herein to any specific commercial product, process, or service by trade name, trademark, manufacturer, or otherwise, does not necessarily constitute or imply its endorsement, recommendation, or favoring by the United States Government or any agency thereof. The views and opinions of authors expressed herein do not necessarily state or reflect those of the United States Government or any agency thereof. 


\title{
DEVELOPING GENERIC DYNAMIC MODELS FOR THE 2030 EASTERN INTERCONNECTION GRID
}

\author{
Gefei Kou \\ Stanton W. Hadley \\ Penn Markham \\ Yilu Liu
}

Date Published: December 2013

Prepared by

OAK RIDGE NATIONAL LABORATORY

Oak Ridge, Tennessee 37831-6283

managed by

UT-BATTELLE, LLC

for the

US DEPARTMENT OF ENERGY

under contract DE-AC05-00OR22725 



\section{CONTENTS}

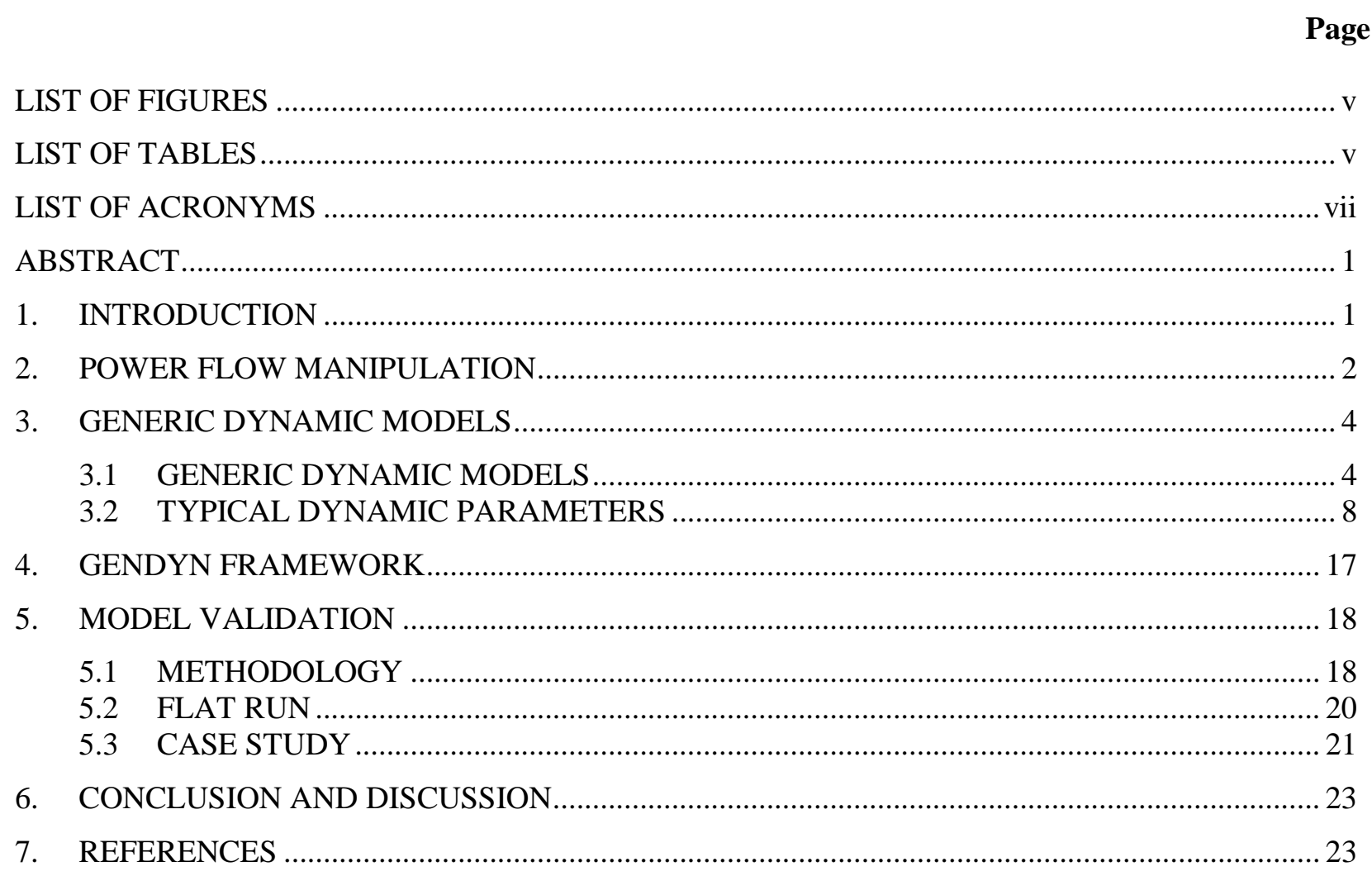





\section{LIST OF FIGURES}

Page

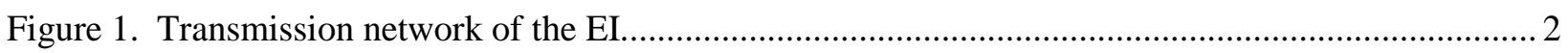

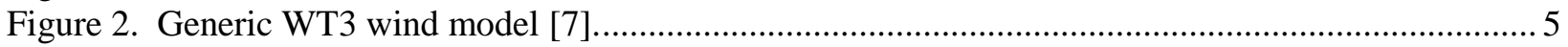

Figure 3. Control diagram of the simplified excitation system [3] ................................................ 5

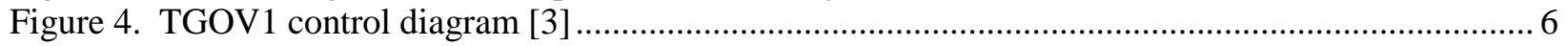

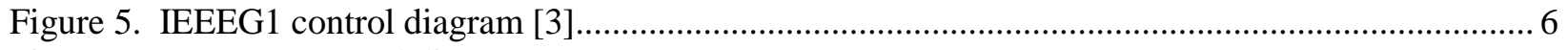

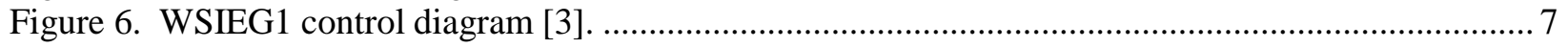

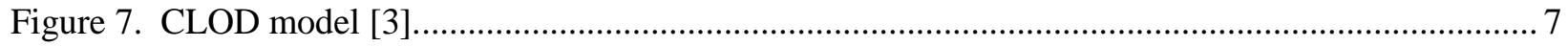

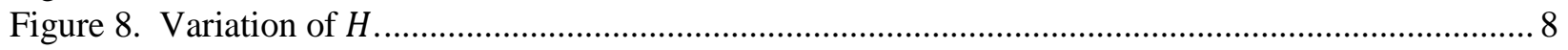

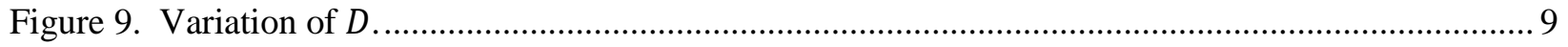

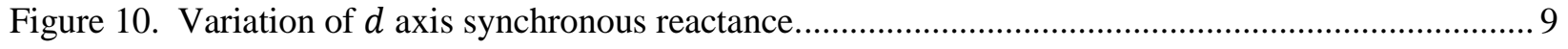

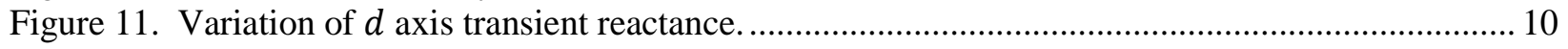

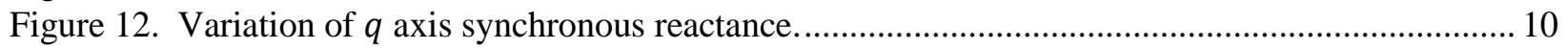

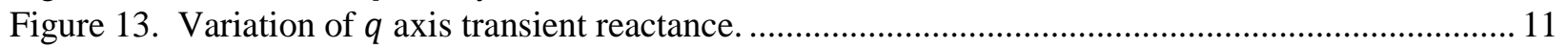

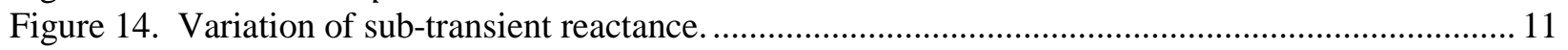

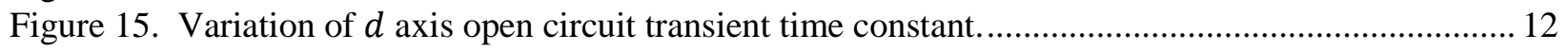

Figure 16. Variation of $d$ axis open circuit sub-transient time constant................................................ 12

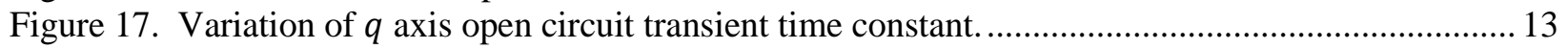

Figure 18. Variation of $q$ axis open circuit sub-transient time constant.................................................. 13

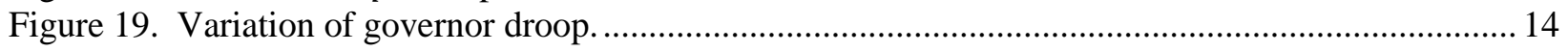

Figure 20. Variation of turbine governor reheater time constant..................................................... 14

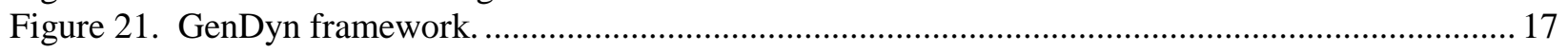

Figure 22. Frequency response with constant power load. ................................................................. 19

Figure 23. Frequency response with constant current/admittance load. ............................................... 20

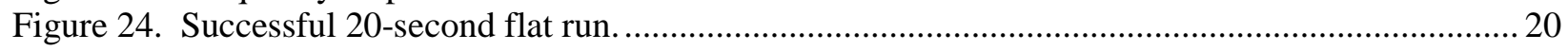

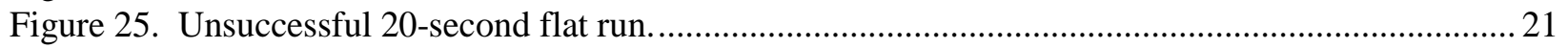

Figure 26. Frequency response of the generation trip in NC. ............................................................... 22

Figure 27. Frequency response of the generation trip in MS........................................................... 22

\section{LIST OF TABLES}

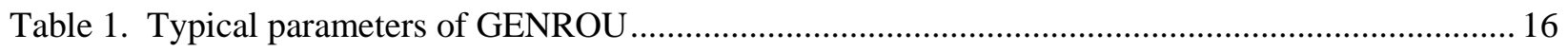

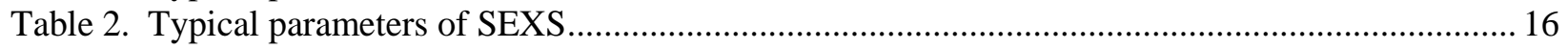

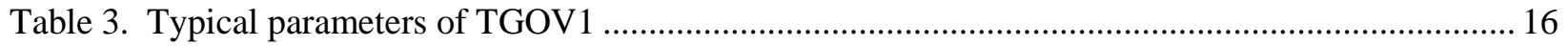





\section{LIST OF ACRONYMS}

$\begin{array}{ll}\text { BAU } & \text { Business as Usual } \\ \text { CRA } & \text { Charles River Associates } \\ \text { CLOD } & \text { complex load model } \\ \text { DAE } & \text { differential algebraic equations } \\ \text { EI } & \text { Eastern Interconnection } \\ \text { EIPC } & \text { Eastern Interconnection Planning Collaborative } \\ \text { FNET/Grideye } & \text { Frequency Monitoring Network/Grideye } \\ \text { HVDC } & \text { High-Voltage Direct Current } \\ \text { MMWG } & \text { Multiregional Modeling Working Group } \\ \text { NERC } & \text { North American Electric Reliability Corporation } \\ \text { OOP } & \text { object-oriented programming } \\ \text { PMU } & \text { Phasor Measurement Unit } \\ \text { PSS } & \text { power system stabilizers } \\ \text { WECC } & \text { Western Electricity Coordinating Council } \\ \text { ZIP } & \text { constant admittance/current/power }\end{array}$





\begin{abstract}
The Eastern Interconnection Planning Collaborative (EIPC) has built three major power flow cases for the 2030 Eastern Interconnection (EI) based on various levels of energy/environmental policy conditions, technology advances, and load growth. Using the power flow cases, this report documents the process of developing the generic 2030 dynamic models using typical dynamic parameters. The constructed model was validated indirectly using the synchronized phasor measurements by removing the wind generation temporarily.
\end{abstract}

\title{
1. INTRODUCTION
}

The Eastern Interconnection (EI) is the largest synchronized electrical power grid in North America and serves $70 \%$ of the U.S. population. To support development of grid capability, the Eastern Interconnection Planning Collaborative (EIPC) has conducted analyses of transmission requirements under a range of future scenarios. In Phase 1, eight futures plus multiple sensitivities per future, for a total of 80 model runs, were developed for the 2030 EI grid based on Charles River Associates' (CRA's) Multi-Region National (MRN) macroeconomic model and their North American Electricity and Environment Model (NEEM). The future scenarios include Business as Usual (BAU), National Carbon Constraint-National Implementation, National Carbon Constraint-Regional Implementation, Aggressive Energy Efficiency/Demand Response/Distributed Generation/Smart Grid, National Renewable Portfolio Standard-National Implementation, National Renewable Portfolio Standard-Regional Implementation (RPS/R), Nuclear Resurgence, and Combined Federal Climate and Energy Policy $\left(\mathrm{CO}_{2}+\right)$. While the eight future scenarios are intended to represent distinct future grid development under various energy and environmental policy drives, sensitivities represent minor variations on each future scenario. Typical sensitivities are load growth and natural gas prices. At the end of Phase 1, three final scenarios, considered to be balanced in terms of policy goals, levels of implementation, transmission build-outs, and total cost, were selected for transmission studies, reliability analysis, and production cost analysis in Phase 2 [1].

In Phase 2, the EI was modeled at a very detailed level (70,000+ buses, 8,000+ generators) in the PSS ${ }^{\circledR} \mathrm{E}$ model for a peak hour and off-peak hour in each case (only the peak hour in the BAU case). Variable generation levels were set at the average values for those blocks. The members of EIPC, in consultation with their stakeholder steering committee, first created a one-line diagram of the EI from their respective long-range plans with some modifications. They then added the generators, loads, lines, and substations that they projected would be needed to approximately match the results from the Phase 1 cases for 2030. These models were run through PSS ${ }^{\circledR} \mathrm{E}$ to first solve with all lines. Once the models gave a solution, various levels of North American Electric Reliability Corporation (NERC) contingency criteria were applied and additional modifications were added to meet the criteria. This resulted in three peak hour and two off-peak hour steady-state PSS ${ }^{\circledR} E$ models covering the three scenarios. The resulting build-outs of the transmission system in these scenarios were then used to model the EI in the GE MAPS model run by CRA [2].

To complement the steady-state study by EIPC, our effort looks at building the dynamic counterpart of the PSS ${ }^{\circledR} E$ models. The completed dynamic model will provide insight into the following aspects.

- Transient stability: the dynamic model enables transient simulations and renders the dynamic behavior of the system subjected to a severe perturbation.

- Small signal stability: the eigenvalue-related analysis can be performed with poorly damped modes identified. 
- Frequency regulation: frequency response can be studied and associated with governor response and new types of generation.

- Renewable integration: the static case models high wind penetration in Nebraska, the Midwest Independent Transmission System Operator (Midwest ISO) region, and the Southwest Power Pool (SPP) region [2]. This allows a realistic study of wind impact on the global system. Solar and energy storage can also be evaluated under the future scenario.

- Control strategies: the EI 2030 dynamic model serves as a large-scale testing bench where widearea control methods can be prototyped and evaluated.

This document records the procedure for converting the $2030 \mathrm{EI}$ static model over to its dynamic equivalents and the model validation work through synchronized phasor measurements. The report is organized as follows: Chapter 2 describes the changes made on the power flow model; Chapter 3 introduces the dynamic models used in the 2030 EI model; the program, GenDyn, that builds the dynamic data file based on power flow data is discussed in Chapter 4; in Chapter 5, the methodology of model validation against the measurement is illustrated and case studies are shown; conclusions are drawn at the end.

It should be pointed out that the generic model is intended for global dynamic behavior studies, such as interconnection-wide frequency responses and inter-area oscillations. If local studies are required on a specific generator, it is recommended to replace the generic parameters for that particular machine or machines nearby by actual parameters.

\section{POWER FLOW MANIPULATION}

The original power flow cases are in PSS ${ }^{\circledR} \mathrm{E}$ format and can be converted to Power World format. The power flow and transient studies are performed in PSS ${ }^{\circledR} \mathrm{E}$ 33.1.1. Figure 1 shows the EI transmission network. The power flow cases contain 70,000+ buses and 8,000+ generators.

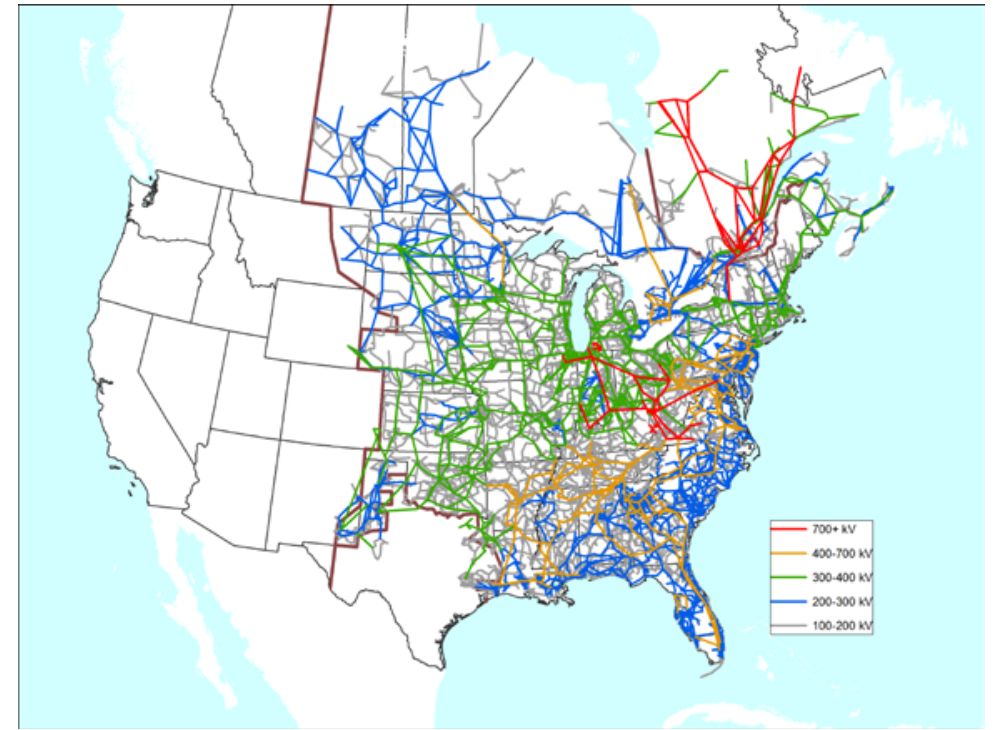

Figure 1. Transmission network of the EI.

Dynamic models use a greater number of variables than a static model. Since the EIPC was only concerned with a static solution, they often did not enter or validate all of the variables needed for a dynamic run. They also made some simplifications in model design that were satisfactory for a static run but not for dynamic analysis. To ensure a successful run of the dynamic simulation, the following procedures were implemented. 


\section{A. HVDC}

Forty High-Voltage Direct Current(HVDC) transmission lines have been modeled connecting to Hydro Quebec, Western Electricity Coordinating Council(WECC), Electric Reliability Council of Texas (ERCOT), and within the EI. As the HVDC and its control are out of scope at the first stage, HVDC is equivalent to positive and negative constant power load on the sending and receiving ends, respectively.

\section{B. Switched Shunt}

There are 6396 switched shunts in the model. However, due to the poor convergence of the switched shunt dynamic model, they are assumed to be locked. Locked switched shunts have constant capacitance/inductance during the dynamic simulation.

\section{MBase}

MBase is a variable that represents the machine capacities in megavolt-amperes (MVA). Its value does not affect a steady-state power flow run and so was not validated in the original EIPC runs. However, all machine-related dynamic models, including generator, exciter, turbine governor, and power system stabilizers (PSS), use MBase as their base for power. In other words, per unit values of the machinerelated dynamic model are based on MBase. Therefore, a random MBase can cause inaccurate simulation results.

MBase should be set about the same as the machine capacity. However, a random value may have been assigned inadvertently during the EIPC static analysis. In some situations in the 2030 EI model the MBase is smaller than the actual machine power output. To ensure the correctness of simulation results, the original MBase is replaced with the value equal to 1.1 times that of the machine's apparent power output. This gives a good estimation of the actual machine capacity.

\section{D. $X_{\text {source }}$}

$X_{\text {source }}$ is the machine internal reactance. It does not affect static power flow results. In dynamic simulations, when GENCLS is used, $X_{\text {source }}$ is the equivalent voltage source reactance. When other detailed generator models are used, $X_{\text {source }}$ should be equal to sub-transient reactance $X^{\prime \prime}$. Therefore, attention should be paid to ensure $X_{\text {source }}=X^{\prime \prime}$.

\section{E. Converting Machines to Negative Load}

In some cases, the generator cannot stabilize in a flat run. It is suggested that GENCLS be used as the generator model or that the machine be converted into a negative load.

\section{F. Identification of Generator Types}

In a static power flow, a specific type of generating unit (including the models for its generator, exciter, turbine governor, and PSS) is not needed. As a result, the EIPC did not specify the technology (hydro, steam, combustion turbine, wind, etc.) for every generator in the model. We matched the names of units from the model to those in various databases available (e.g., MMWG or Multiregional Modeling Working Group) cases from Energy Visuals, EIA Form 860 data from Energy Information Administration) in order to assign technology types. Many plants did not exist in these databases since they were added specifically for the EIPC 2030 cases. Some information in the EIPC case files helped to identify the plants; others required engineering judgment based on size, capacity factor, and location. As part of this 
effort, latitude and longitude estimates were set for each generating unit and all buses above $200 \mathrm{kV}$. These data are useful for geographical visualization when data is ported to the PowerWorld simulator.

To build a valid power flow case, HVDCs and unstable machines are converted to equivalent load. MBase and $X_{\text {source }}$ are adjusted. A power flow run is recommended even if the case is already solved. Afterwards, the load conversion is performed. A typical load composite is $50 \%$ constant current and $50 \%$ constant impedance. Finally, the switched shunt control mode is changed to locked.

\section{GENERIC DYNAMIC MODELS}

The transient simulation process integrates three steps: first, differential algebraic equations (DAEs), describing the dynamic behavior of physical devices and the transmission network, are formulated. Second, a set of constant and variable parameters that describe the detailed condition of the physical components are determined. Initial conditions of DAEs are obtained by the power flow solution. Next, numerical integration methods are applied to the DAEs formulated in the first step along with the parameters and initial conditions determined in the second step [3]. The general form of transient response calculation can be expressed in the following form [4]-[6]:

$$
\begin{aligned}
& \dot{x}=f(x, V), \\
& I=Y V,
\end{aligned}
$$

where $\mathrm{x}$ is the state variable of synchronous generators, excitation, turbine governors, wind machines, HVDC, and other dynamic devices. V and I are node voltage and current vectors. Y is the node admittance matrix of the network structure. Equations (1) and (2) can be solved either by a partitioned-solution approach or a simultaneous-solution approach [4][5].

The commercial-grade transient simulation solvers, such as PSS ${ }^{\circledR}$ E by Siemens PTI, PSLF by GE, and TSAT by Powertech, facilitate the automated formulation of the system dynamic equations, integration of power flow solutions, and numerical computations. To enable a successful transient simulation run, the user only needs to choose the appropriate dynamic model and determine a set of model parameters required by the model. Note that the dynamic model parameters are not necessary for power flow solutions and need to be obtained either from manufactures’ data or by field tests.

When constructing the 2030 EI dynamic model, no dynamic parameters were readily available. Even if some current model parameters were accessible, there is no guarantee of data accuracy for a system with more than 70,000 buses and 8,000 machines, let alone the infrastructure to be built in the future.

Therefore, our attempt is to create the dynamic model with generic parameters so that the future grid can be simulated as closely as possible. To this end, a software framework is built to automatically create the dynamic model based on power flow solutions. A trial-and-error process is adopted to continuously tune the model parameter so that the simulated frequency responses match with the measurement.

\subsection{GENERIC DYNAMIC MODELS}

The actual EI grid contains an enormous amount of dynamic components, such as generators, excitation systems, turbine governors, and load. To accurately simulate the system response to any perturbation, efforts have been made to model the variations within each model category. The following section lists the dynamic models used in the 2030 EI model. It should be mentioned that the models comply with the PSS ${ }^{\circledR}$ E nomenclature [3].

The round rotor generator model (GENROU) for thermal plants and the salient pole generator model (GENSAL) for hydro plants are represented. The voltage-behind-reactance model (GENCLS) is also used 
in case successful machine initialization cannot be reached. Wind farms are represented by a generic-type three wind model (WT3), as shown in Figure 2, and GE wind model (GEWT) [7]-[9].

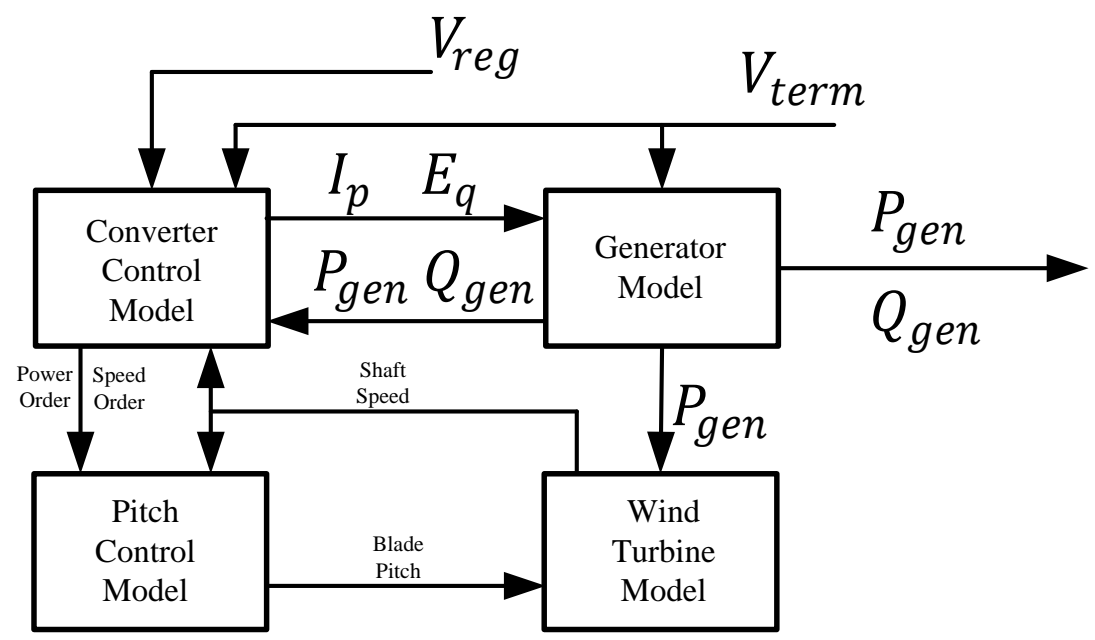

Figure 2. Generic WT3 wind model.

The excitation system serves the function of voltage and reactive power control. The types of excitation system installed fall into a broad range of categories, including DC excitation systems, AC excitation systems, and static excitation systems [5][10]. DC excitation systems have given way to the other two, characterized by fast acting and high gain. To capture the principal dynamic features of modern excitation systems while not being limited to the detailed design, the simplified excitation system mode (SEXS) is adopted [3]. Excitation time constant $\mathrm{T}_{\mathrm{E}}$, gain $\mathrm{K}$, over-excitation limit $\mathrm{E}_{\mathrm{MAX}}$ set by generator field winding thermal constraint, and under-excitation limit $\mathrm{E}_{\mathrm{MIN}}$ set by the stability constraint or the stator core end-region heating limit provide a general depiction of the excitation system. The compensator provides a transient gain reduction of $\mathrm{T}_{\mathrm{A}} / \mathrm{T}_{\mathrm{B}}$, which allows satisfactory performance on the full frequency spectrum (Figure 3).

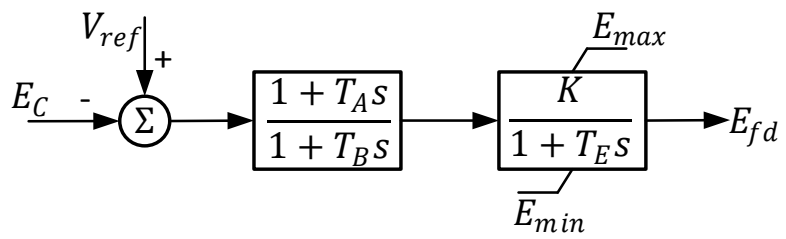

Figure 3. Control diagram of the simplified excitation system.

The turbine governor system is essential to real power and frequency control. The dynamic performance may differ vastly depending on the type of turbines, including steam, hydro, and gas. To represent variations in turbine governor systems, several types of turbine governor models are considered. TGOV1 is a simplified representation of steam turbine governors (Figure 4). Governor action, reheater time constant, and the ratio of high-pressure turbine are recognized in this model. IEEE type 1 (IEEEG1) turbine governor model is used to represent steam turbines in a wide range of designs including nonreheat, tandem compound, and cross-compound types (Figure 5). The hydro turbine governor is represented by HYGOV, which models the penstock with unrestricted head race and tail race, but no surge tank. GAST is used to characterize gas turbine-governor systems. References [3], [5], and [11] give detailed descriptions of the models aforementioned. 


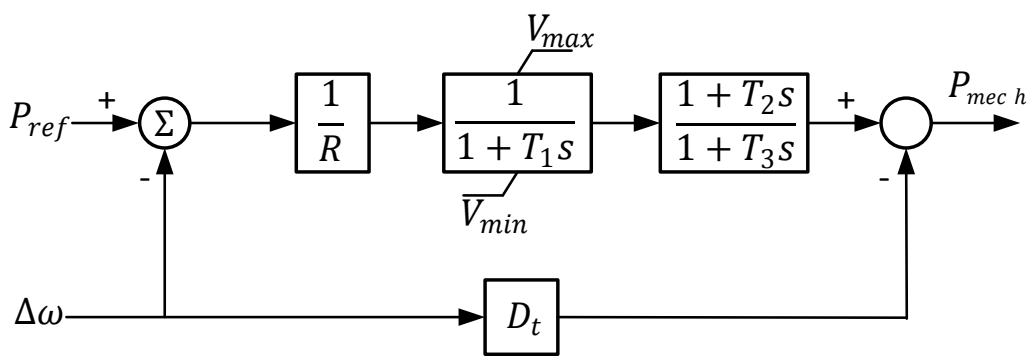

Figure 4. TGOV1 control diagram.

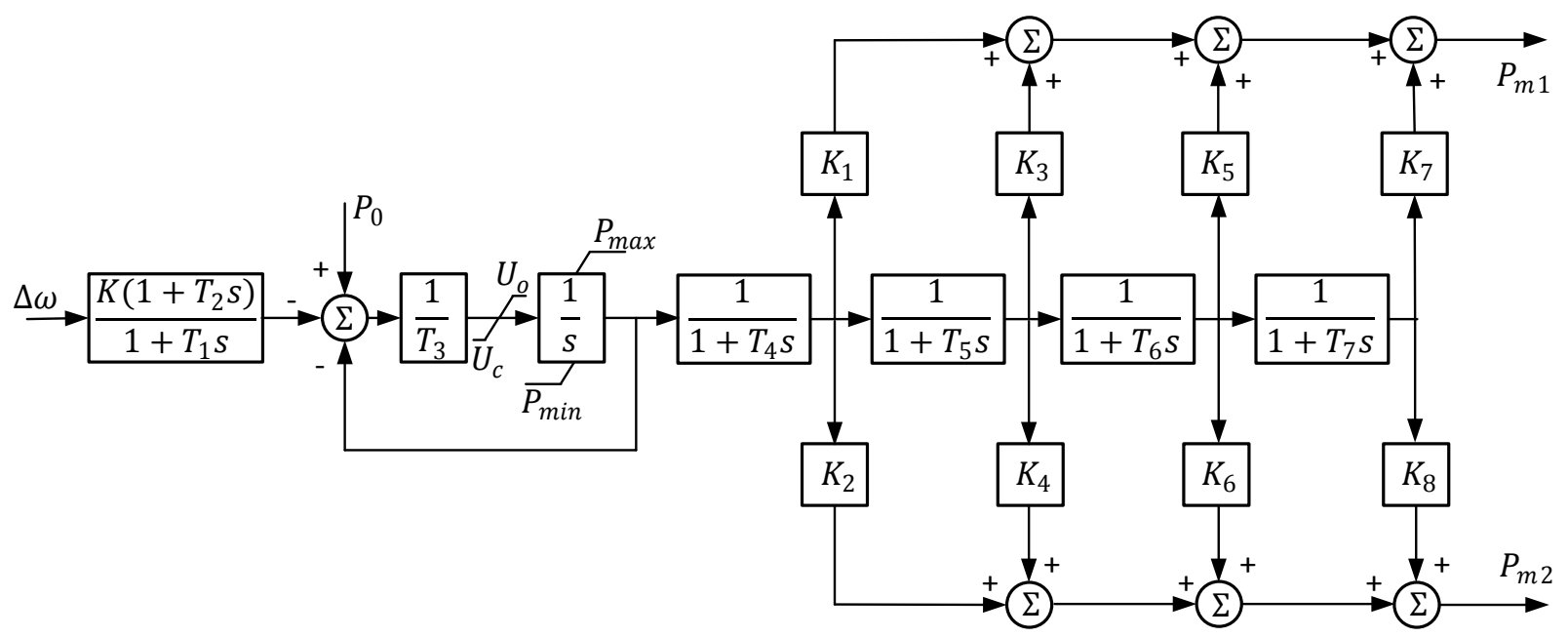

Figure 5. IEEEG1 control diagram.

It has been observed that the measured frequency governing response in the EI system is considerably less than that of computer-modeled simulation response [12][13]. In [14], it is argued that governor deadband can contribute to the decline of governor response. To take into account the governor deadband, the IEEE type 1 turbine governor model with deadband, WSIEG1 [3], is adopted for extended frequency response studies (Figure 6). 

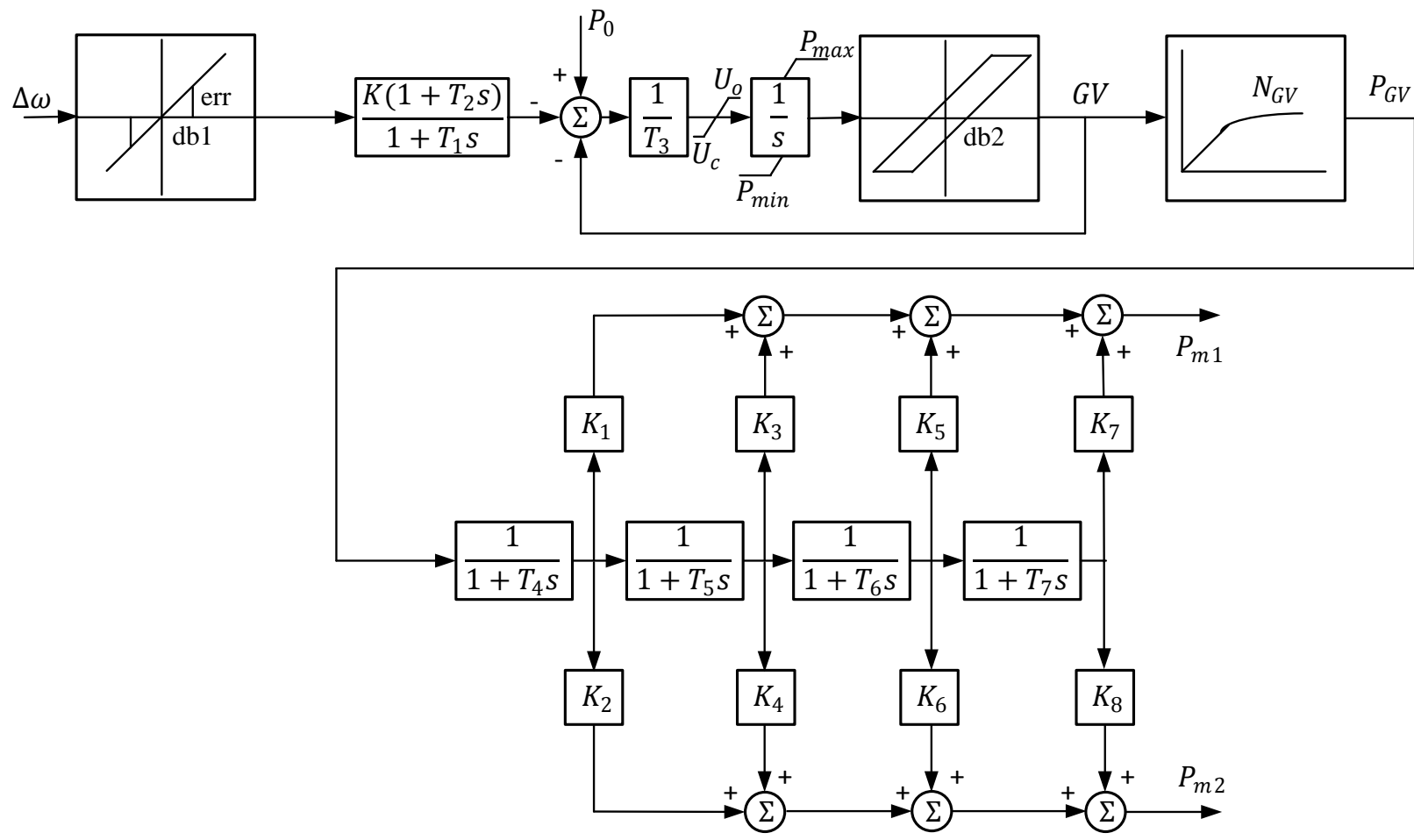

Figure 6. WSIEG1 control diagram.

Constant admittance/current/power (ZIP) load modeling approach is widely used in industry practice [15]. However, ZIP load assumes a static (algebraic) correlation between load power and bus voltage, which apparently neglects the dynamics of component devices such as induction motors, discharge lighting, and saturated transformers. It is reported that detailed dynamic load modeling approaches render more accurate simulation results than the static modeling approaches [16]-[18]. Therefore, the $2030 \mathrm{EI}$ dynamic model adopts both a ZIP load model and complex load model (CLOD [3]), which represents motors, discharging lighting, saturated transformers, and static load (Figure 7).

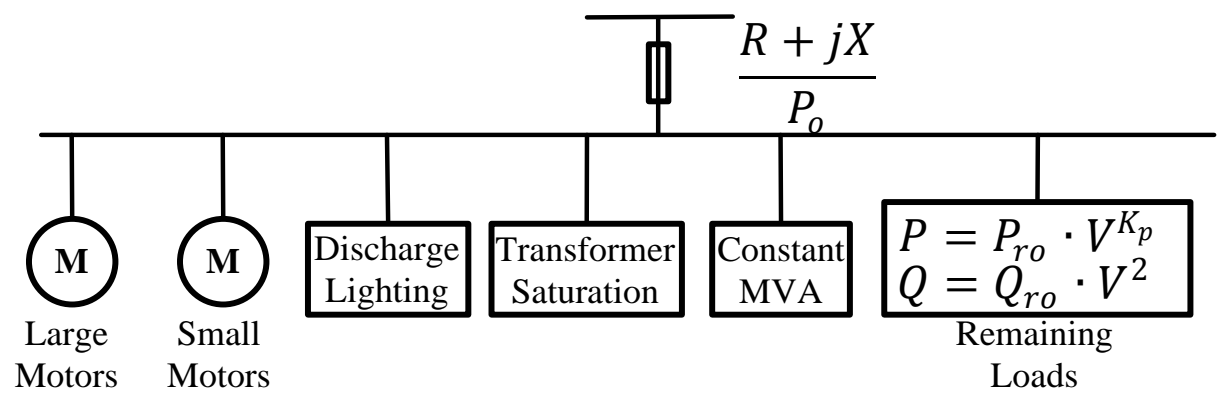

Figure 7. CLOD model.

It should be noted that the models used above help build the base case. To represent the system in greater details, more comprehensive models can be added. 


\subsection{TYPICAL DYNAMIC PARAMETERS}

Another issue that had to be addressed is the model parameters. Credible model parameters are indispensable to the fidelity of simulation results. However, most model parameters are either unavailable or nonexistent for future infrastructures. To resolve this issue, the generic parameter approach is adopted.

According to References [5] and [6], the generators' parameters fall into a narrow range. References [10] and [11] provide typical parameters on excitation and turbine governor systems. A statistic study is conducted to survey variation in dynamic parameters in the current EI model. It is concluded that most dynamic parameters converge to a typical value with little variation. Figures 8-18 give examples of parameter variations for GENROU.

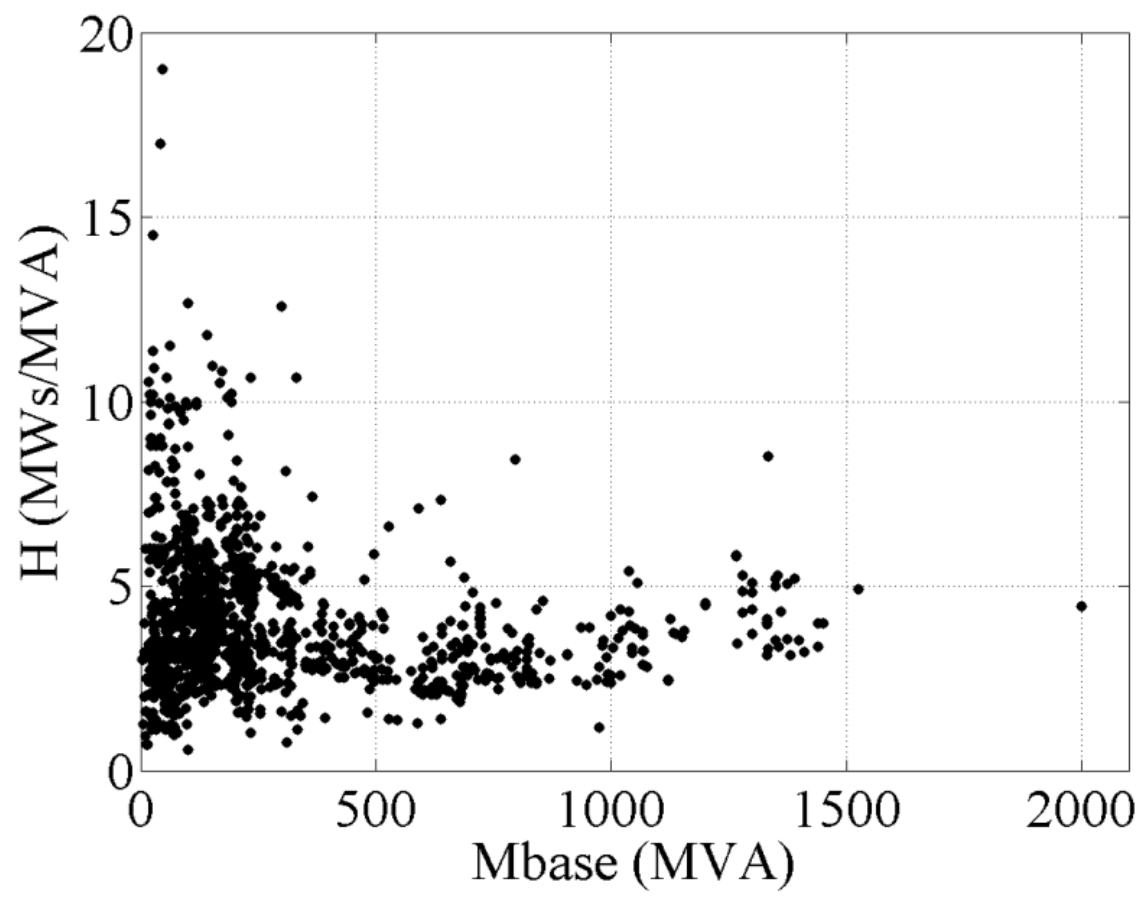

Figure 8. Variation of $\boldsymbol{H}$. 


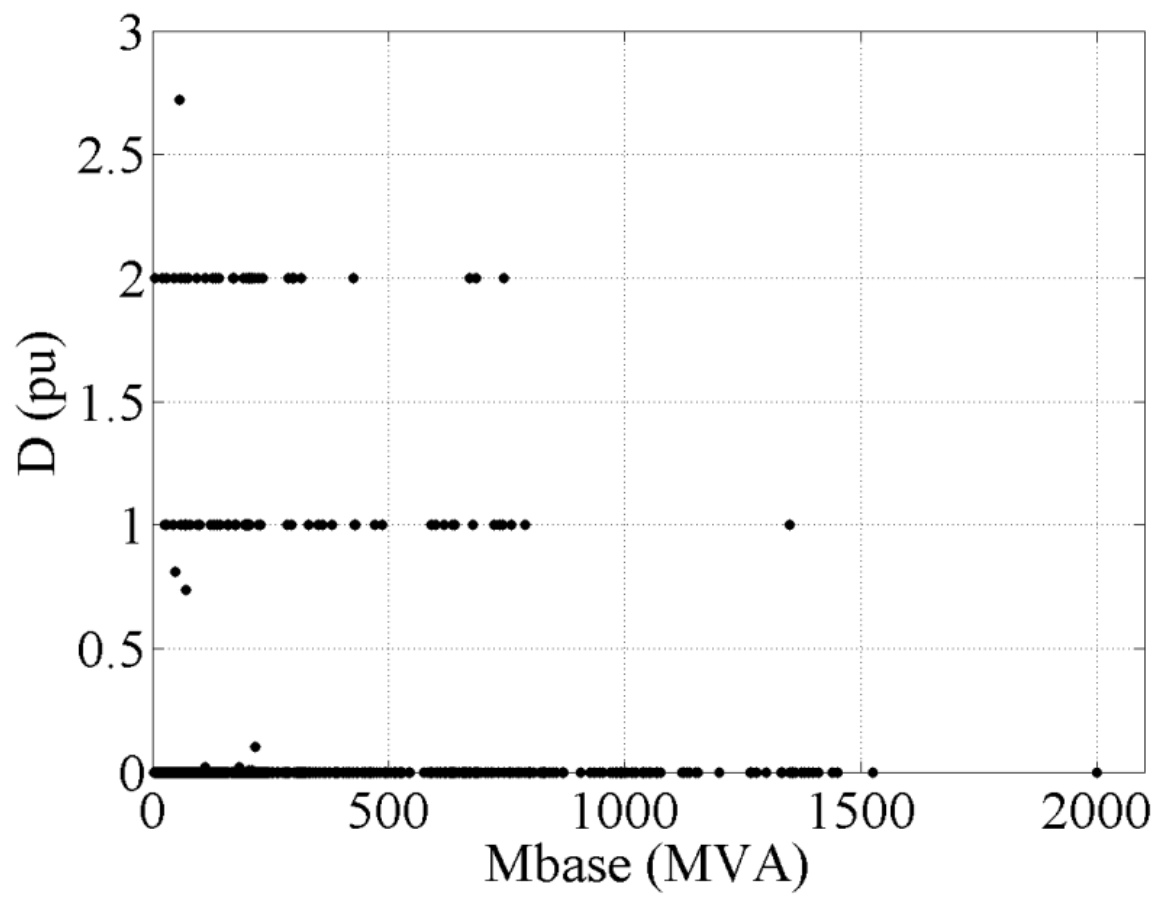

Figure 9. Variation of $D$.

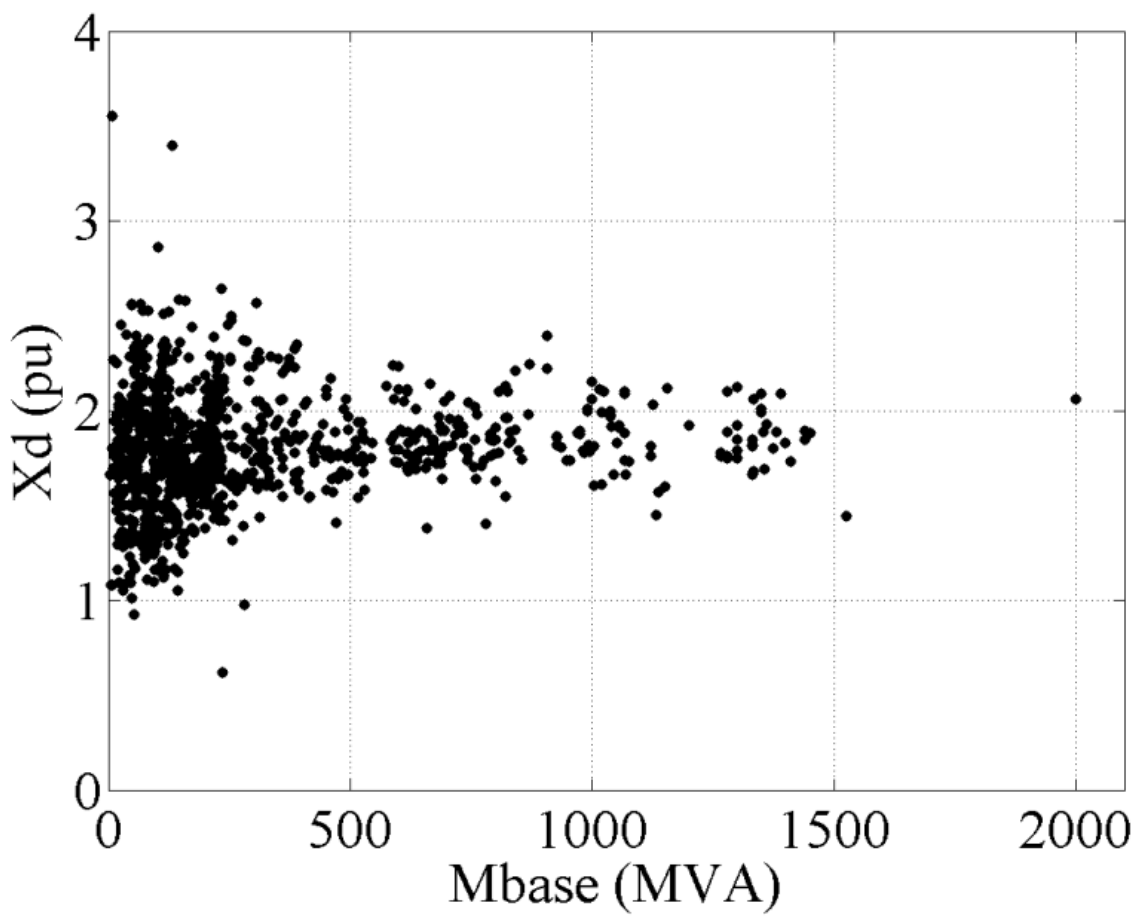

Figure 10. Variation of $\boldsymbol{d}$ axis synchronous reactance. 




Figure 11. Variation of $\boldsymbol{d}$ axis transient reactance.

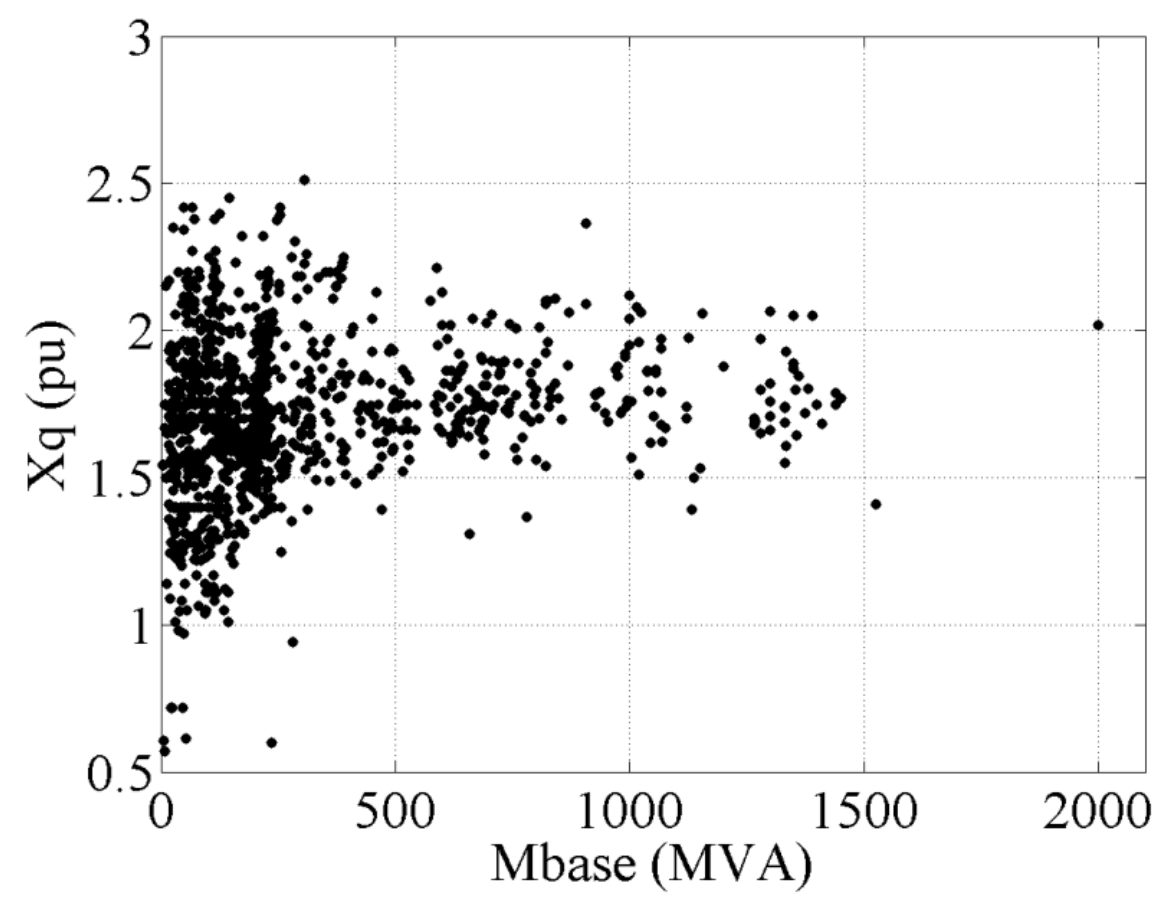

Figure 12. Variation of $q$ axis synchronous reactance. 


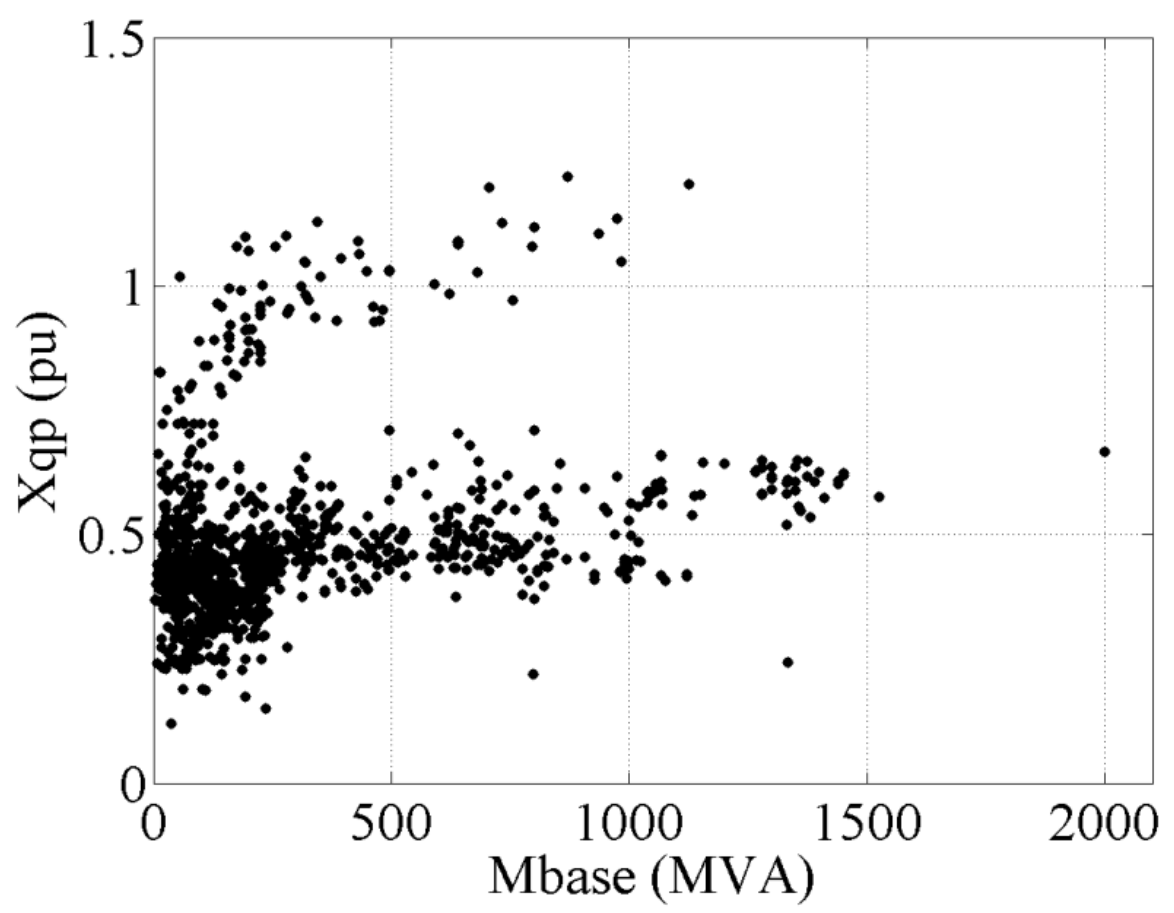

Figure 13. Variation of $q$ axis transient reactance.

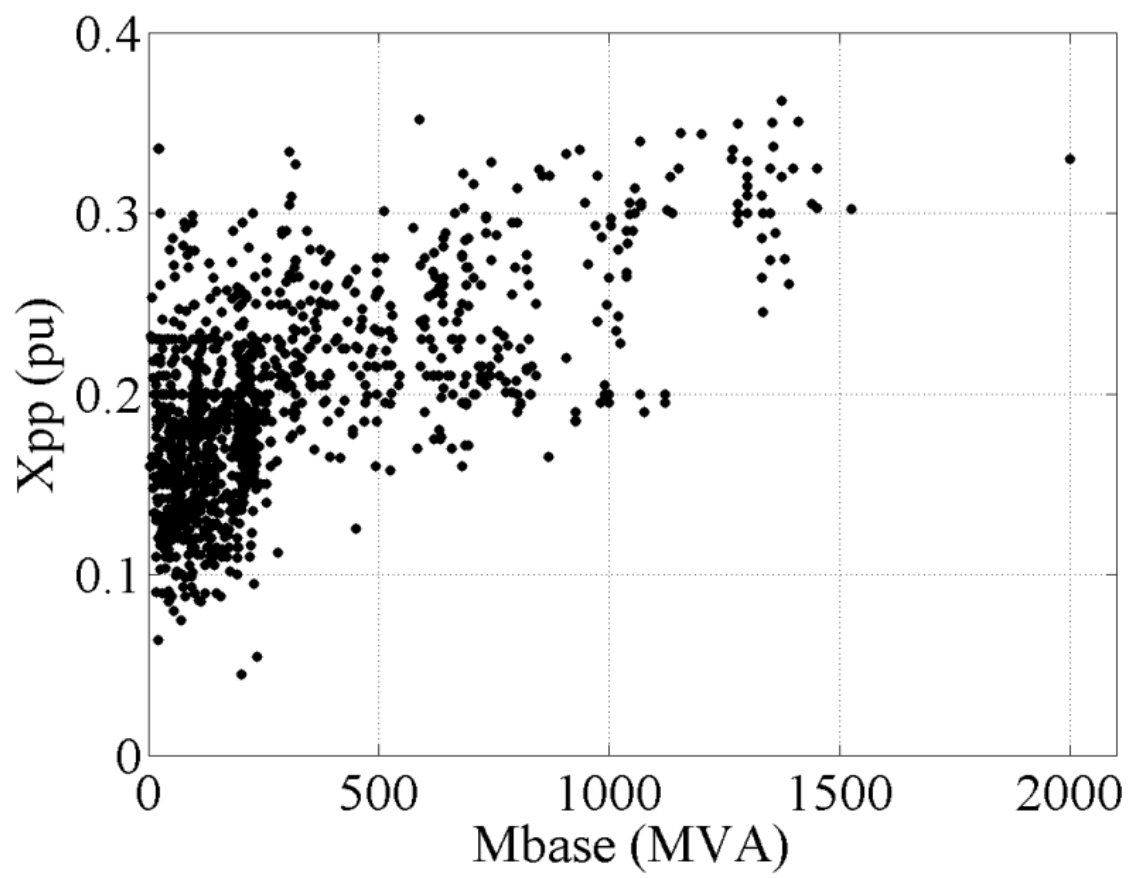

Figure 14. Variation of sub-transient reactance. 


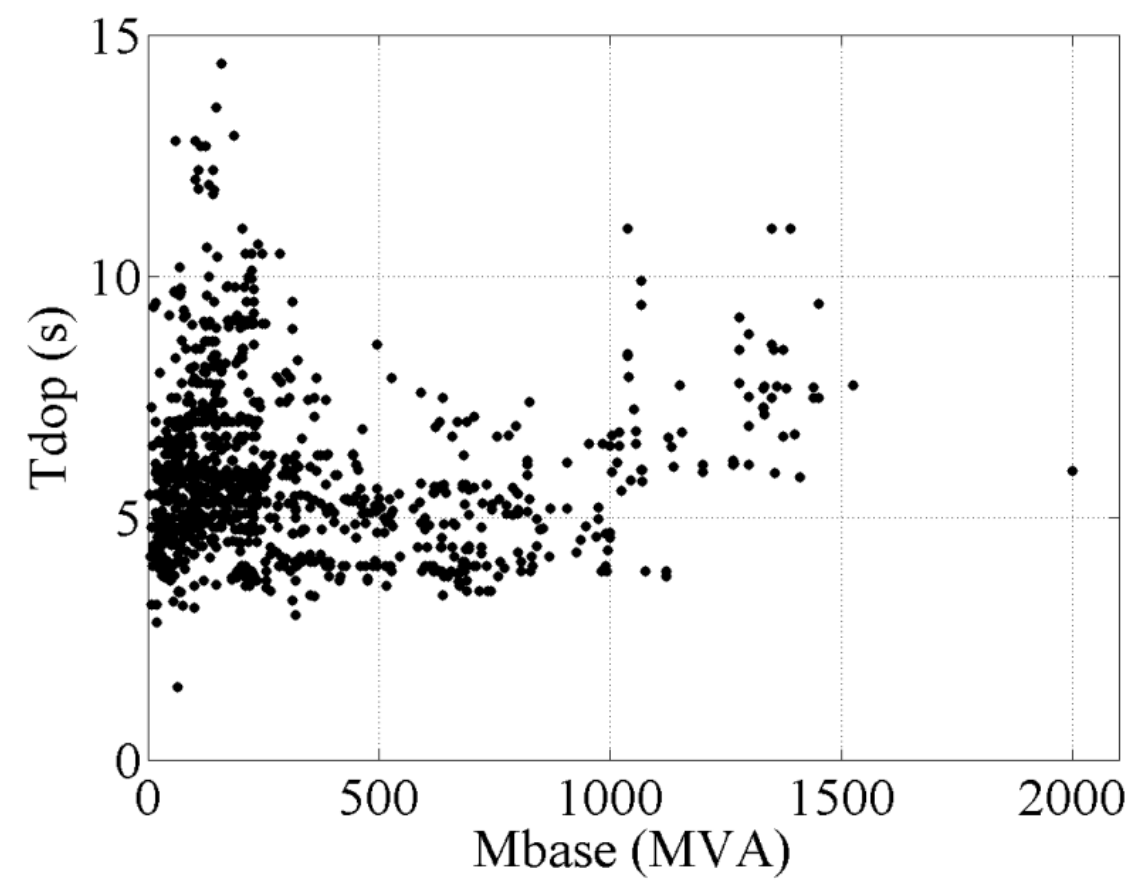

Figure 15. Variation of $d$ axis open circuit transient time constant.

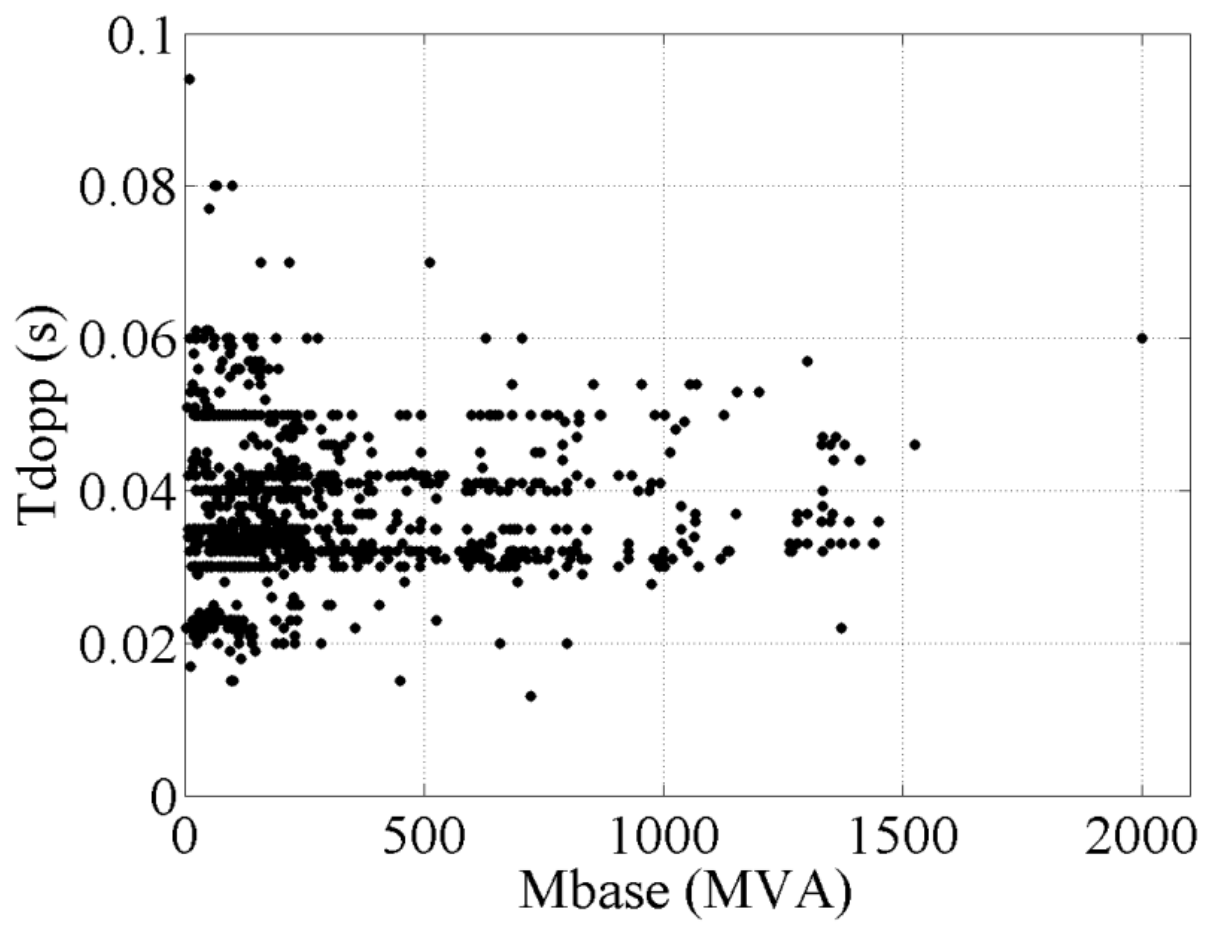

Figure 16. Variation of $d$ axis open circuit sub-transient time constant. 


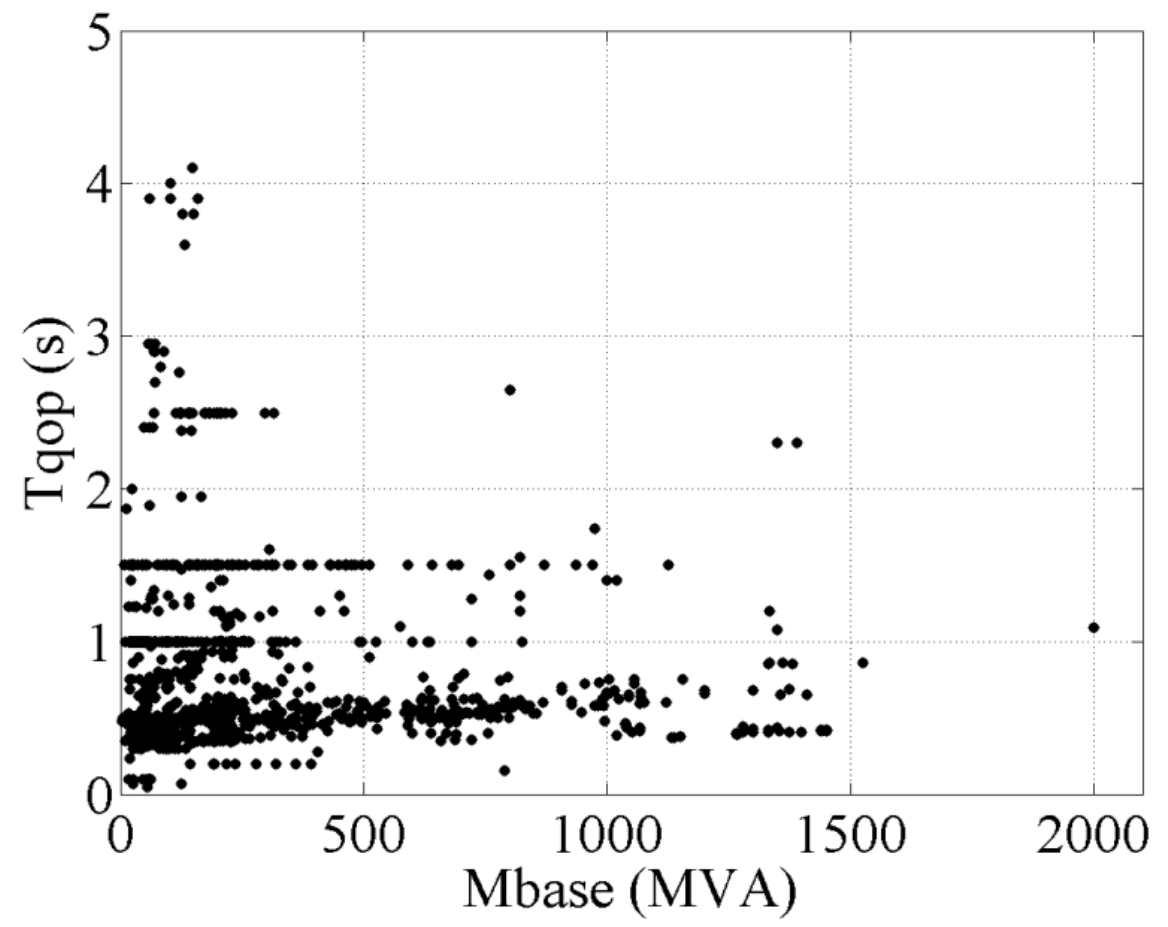

Figure 17. Variation of $q$ axis open circuit transient time constant.

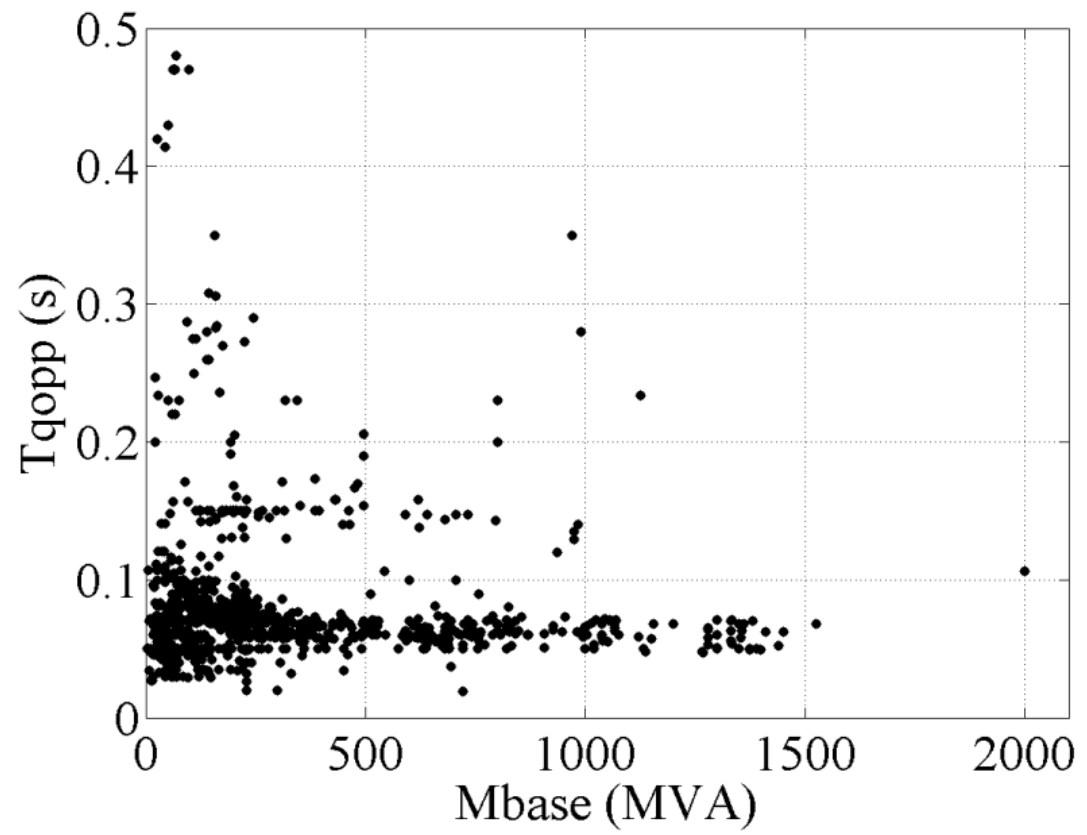

Figure 18. Variation of $q$ axis open circuit sub-transient time constant.

Figures 19 and 20 give parameter variations of model TGOV1. 


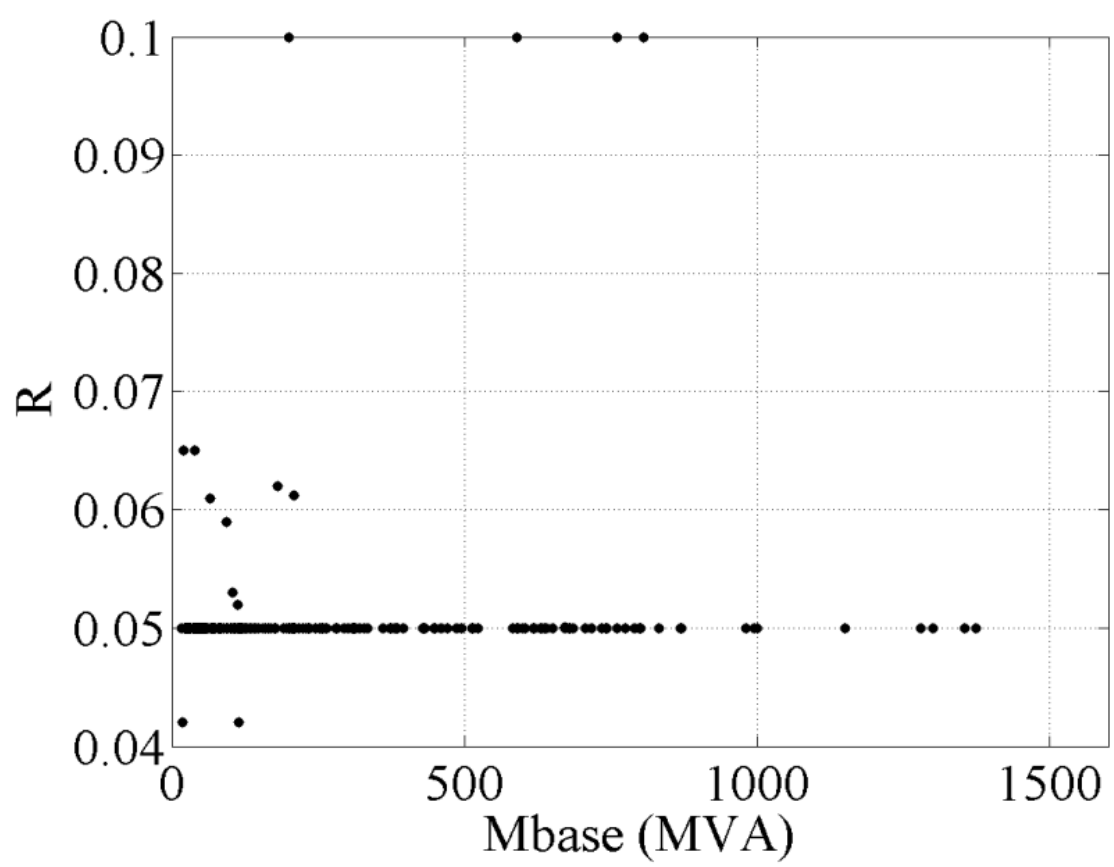

Figure 19. Variation of governor droop.

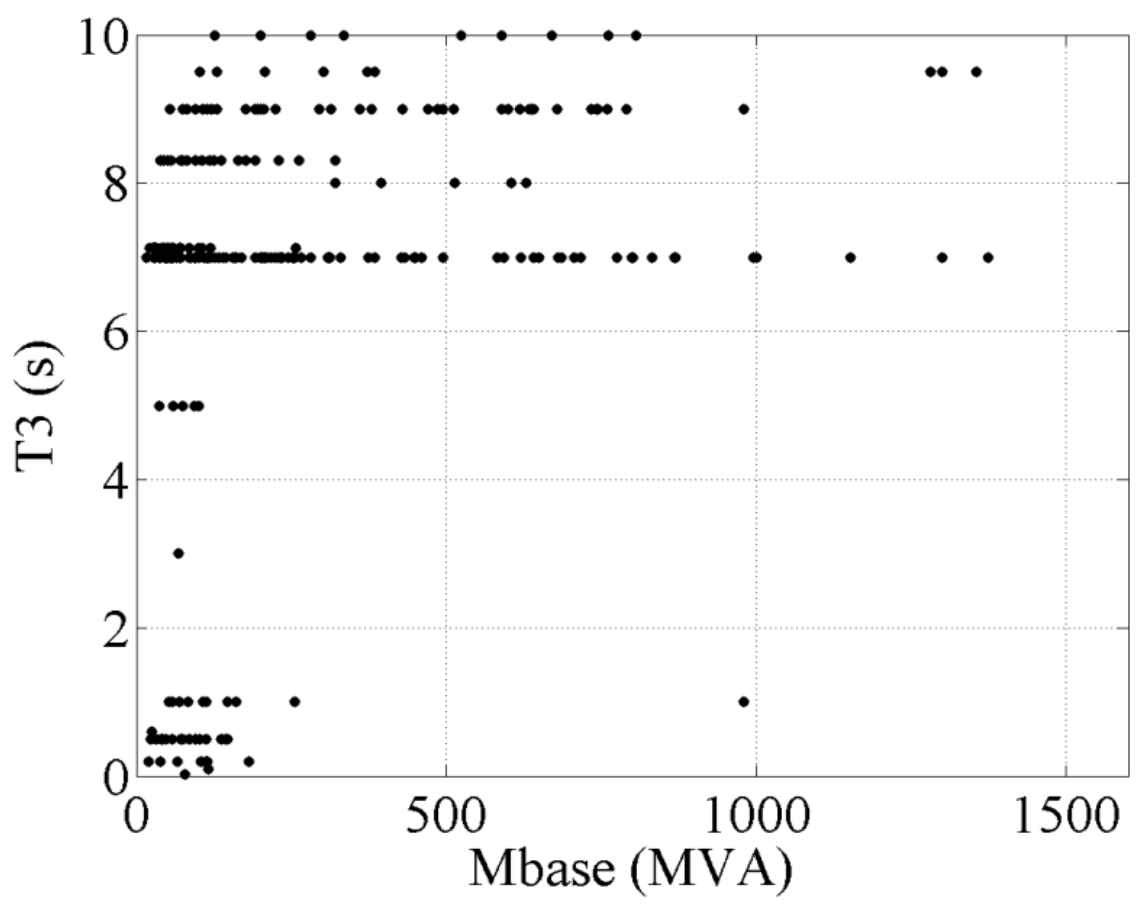

Figure 20. Variation of turbine governor reheater time constant.

It is concluded that the design parameters, such as machine reactance, tend to converge to a typical value, while control parameters, which are determined by field tests, may vary. However, although the generic 
model approach may not simulate the real system in a perfect match, it is able to capture the major dynamic characteristics. Plus, its reasonableness is guaranteed.

Tables 1-3 list some typical dynamic model parameters. 
Table 1. Typical parameters of GENROU

\begin{tabular}{|c|l|l|l|}
\hline CONs & $\#$ & Value & \multicolumn{1}{|c|}{ Description } \\
\hline $\mathrm{J}$ & & 6.0000 & $\mathrm{~T}^{\prime}$ do $(>0)(\mathrm{sec})$ \\
\hline $\mathrm{J}+1$ & & 0.5000 & $\mathrm{~T}^{\prime \prime}$ do $(>0)(\mathrm{sec})$ \\
\hline $\mathrm{J}+2$ & & 1.0000 & $\mathrm{~T}_{\mathrm{qo}}^{\prime}(>0)(\mathrm{sec})$ \\
\hline $\mathrm{J}+3$ & & 0.0500 & $\mathrm{~T}^{\prime \prime} \mathrm{qo}(>0)(\mathrm{sec})$ \\
\hline $\mathrm{J}+4$ & 3.9398 & $\mathrm{H}$, Inertia \\
\hline $\mathrm{J}+5$ & & 0.0000 & $\mathrm{D}$, Speed damping \\
\hline $\mathrm{J}+6$ & & 1.4000 & $\mathrm{X}_{\mathrm{d}}$ \\
\hline $\mathrm{J}+7$ & & 1.3500 & $\mathrm{X}_{\mathrm{q}}$ \\
\hline $\mathrm{J}+8$ & & 0.3000 & $\mathrm{X}_{\mathrm{d}}^{\prime}$ \\
\hline $\mathrm{J}+9$ & & 0.6000 & $\mathrm{X}_{\mathrm{q}}^{\prime}$ \\
\hline $\mathrm{J}+10$ & & 0.2000 & $\mathrm{X}^{\prime \prime} \mathrm{d}=\mathrm{X}^{\prime \prime} \mathrm{q}$ \\
\hline $\mathrm{J}+11$ & & 0.1000 & $\mathrm{X}_{\mathrm{l}}$ \\
\hline $\mathrm{J}+12$ & & 0.0300 & $\mathrm{~S}(1.0)$ \\
\hline $\mathrm{J}+13$ & & 0.4000 & $\mathrm{~S}(1.2)$ \\
\hline
\end{tabular}

Table 2. Typical parameters of SEXS

\begin{tabular}{|c|l|l|l|}
\hline CONs & $\#$ & \multicolumn{1}{|c|}{ Value } & \multicolumn{1}{|c|}{ Description } \\
\hline $\mathrm{J}$ & & 0.1000 & $\mathrm{~T}_{\mathrm{A}} / \mathrm{T}_{\mathrm{B}}$ \\
\hline $\mathrm{J}+1$ & & 10.000 & $\mathrm{~T}_{\mathrm{B}}(>0)(\mathrm{sec})$ \\
\hline $\mathrm{J}+2$ & & 100 & $\mathrm{~K}$ \\
\hline $\mathrm{J}+3$ & & 0.1000 & $\mathrm{~T}_{\mathrm{E}}(\mathrm{sec})$ \\
\hline $\mathrm{J}+4$ & & -4.0000 & EMIN (pu on EFD base) \\
\hline $\mathrm{J}+5$ & & 5.0000 & EMAX (pu on EFD base) \\
\hline
\end{tabular}

Table 3. Typical parameters of TGOV1

\begin{tabular}{|c|c|c|l|}
\hline CONs & $\#$ & Value & \multicolumn{1}{|c|}{ Description } \\
\hline $\mathrm{J}$ & & 0.0500 & $\mathrm{R}$ \\
\hline $\mathrm{J}+1$ & & 0.5000 & $\mathrm{~T} 1(>0)(\mathrm{sec})$ \\
\hline $\mathrm{J}+2$ & & 1.0000 & $\mathrm{VMAX}$ \\
\hline $\mathrm{J}+3$ & & 0.0000 & $\mathrm{VMIN}$ \\
\hline $\mathrm{J}+4$ & & 6.0000 & $\mathrm{~T} 2(\mathrm{sec})$ \\
\hline $\mathrm{J}+5$ & & 6.0000 & $\mathrm{~T} 3(>0)(\mathrm{sec})$ \\
\hline $\mathrm{J}+6$ & & 0.0000 & $\mathrm{Dt}$ \\
\hline
\end{tabular}




\section{GENDYN FRAMEWORK}

Transient simulation requires the dynamic parameter set. Therefore, a computer program is necessary to realize the following functions.

- Read and parse power flow solution: collect static components that require a dynamic model in transient simulation; and correct erroneous data.

- Assign dynamic models and generic parameters to dynamic components.

- $\quad$ Output the dynamic parameter file in certain format, for example, .dyr in PSS ${ }^{\circledR} E$.

Additionally, it is desirable that the program features modularity, which allows parsing and writing data in different formats and extending of model libraries. To this end, a computer program named GenDyn is created in Python and adopts an object-oriented programming (OOP) approach. Additional information is available in Reference [19] regarding the application of OOP to power system modeling.

Figure 21 illustrates the framework of GenDyn. It first reads the power flow data through the data parser and feeds the generator class with machine identifiers, power generation, power limits, and other operation data. The generator class also stores the machine, exciter, turbine governor, and power system stabilizer (PSS) model. By default, GENROU, SEXS, and TGOV1 are assumed. A separate input file (not shown in Fig. 21) changes the default models for generators that require non-default settings. For instance, the hydro units are represented with GENSAL and HYGOV. Afterwards, the dynamic component class is created to each type of dynamic model. The dynamic component class stores machine identifiers, assumed dynamic parameters, and static operation data if necessary. Finally, the dynamic parameters are output in a specific format.

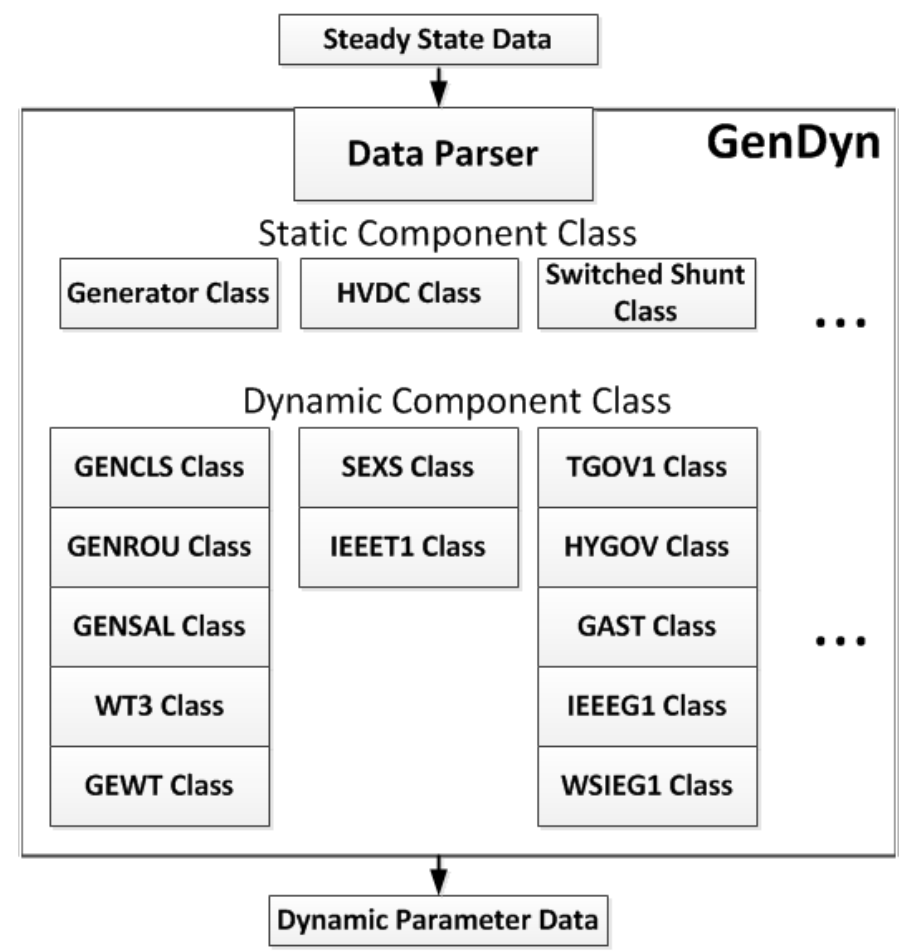

Figure 21. GenDyn framework. 


\section{MODEL VALIDATION}

\subsection{METHODOLOGY}

Efforts have been made using synchronized phasor measurement to validate dynamic models so that the simulation results can accurately reflect performance of the actual system [20][21][23]. To ensure the model accuracy, the 2030 EI dynamic model is validated against synchronized phasor measurements by the frequency monitoring network FNET/Grideye, which is essentially a single-phase Phasor Measurement Unit (PMU) network at the distribution level [22][23]. It is noted that since current wind penetration is relatively low, the 2030 EI dynamic model has to be indirectly validated by replacing wind machines with conventional generation.

To match the measured frequency response with the simulation, three parameters are adjusted, that is, machine inertia, load composite ratio, and percent of blocked governors.

The machine inertia is closely related to the oscillation frequency. Take the single machine infinite bus (SMIB) system as the example using the classical machine model (voltage-behind-reactance model). Linearize the swing equations around the operating point $\delta=\delta_{0}$ :

$$
\begin{gathered}
\mathrm{d} \Delta \omega_{\mathrm{r}}=\frac{1}{2 \mathrm{H}}\left(\Delta \mathrm{T}_{\mathrm{m}}-\Delta \mathrm{T}_{\mathrm{e}}-\mathrm{K}_{\mathrm{D}} \Delta \omega_{\mathrm{r}}\right), \\
\mathrm{d} \Delta \delta=\omega_{0} \Delta \omega_{\mathrm{r}},
\end{gathered}
$$

where $\Delta \mathrm{T}_{\mathrm{e}}=\frac{\mathrm{E}^{\prime} \mathrm{E}_{\mathrm{inf}}}{\mathrm{X}_{\mathrm{eq}}} \cos \left(\delta_{0}\right) \Delta \delta=\mathrm{K}_{\mathrm{S}} \Delta \delta$. Substituting $\Delta \omega_{\mathrm{r}}$ with $\mathrm{d} \Delta \delta / \omega_{0}$ and applying Laplace transform, the characteristic equation regarding $\Delta \delta$ is

$$
\mathrm{s}^{2}+\frac{\mathrm{K}_{\mathrm{D}}}{2 \mathrm{H}} \mathrm{s}+\frac{\mathrm{K}_{\mathrm{S}} \omega_{0}}{2 \mathrm{H}}=0 .
$$

$\mathrm{K}_{\mathrm{D}}$ approximates the combined damping torque effect from field winding, amortisseurs, and excitation systems. The damped frequency can be derived as

$$
\omega_{\mathrm{d}}=\mathrm{w}_{\mathrm{n}} \sqrt{1-\zeta^{2}}=\sqrt{-\frac{\mathrm{K}_{\mathrm{D}}^{2}}{16} \frac{1}{\mathrm{H}^{2}}+\frac{\mathrm{K}_{\mathrm{S}} \omega_{0}}{2} \frac{1}{\mathrm{H}}} .
$$

Practically, $\omega_{\mathrm{d}}$ is monotonically decreasing with regards to $\mathrm{H}$. Therefore, the simulated oscillation frequency can be adjusted by machine inertia.

The composite ratio of ZIP load is correlated to the oscillation damping. While the constant power load absorbs invariant real and reactive power during transients, the constant current and constant admittance load are voltage sensitive. Equations (7)-(10) characterize the relationship between real/reactive power and bus voltage:

$$
\begin{aligned}
& P_{\text {c.c. }}=P_{0}\left(\frac{\mathrm{V}}{\mathrm{V}_{0}}\right) \\
& \mathrm{Q}_{\text {c.c. }}=\mathrm{Q}_{0}\left(\frac{\mathrm{V}}{\mathrm{V}_{0}}\right), \\
& \mathrm{P}_{\text {c.a. }}=\mathrm{P}_{0}\left(\frac{\mathrm{V}}{\mathrm{V}_{0}}\right)^{2}, \\
& \mathrm{Q}_{\text {c.a. }}=\mathrm{Q}_{0}\left(\frac{\mathrm{V}}{\mathrm{V}_{0}}\right)^{2} .
\end{aligned}
$$


When the system is subjected to a voltage excursion, constant current/admittance load is able to mitigate the perturbation by absorbing oscillation energy. Figures 22 and 23 show the frequency response to a 590 MW generation trip. The load is set at constant power in the first plot. The second plot assumes $60 \%$ constant current plus $40 \%$ constant admittance in real power and $50 \%$ constant current plus 50\% constant admittance in reactive power. It is noted that a higher ratio of constant current and admittance composite load causes a larger damping ratio.

As mentioned above, there exists a large discrepancy in governor frequency response between measurement and simulation results [12][13]. It is reported that in practice some generators are base loaded and do not contribute during frequency excursion [24]. It is suggested that a large percentage of turbine governors should be blocked in the simulation in order to match up with the measurement [23]. Equation (11) illustrates the impact of blocking governors:

$$
\Delta \mathrm{f}=\mathrm{Rf}_{\text {base }} \Delta \mathrm{P} / \mathrm{S}_{\text {base }}
$$

$\mathrm{R}$ is the governor droop, which has a typical value of 0.05 in practice. When a certain amount of generation, $\Delta \mathrm{P}$, is lost, the same amount of generation should be compensated in order to prevent the frequency from dropping, neglecting the frequency-sensitive load. Therefore, if there are fewer turbine governors reacting, the power base $S_{\text {base }}$ decreases accordingly. Therefore, a larger frequency deviation $\Delta \mathrm{f}$ is observed.

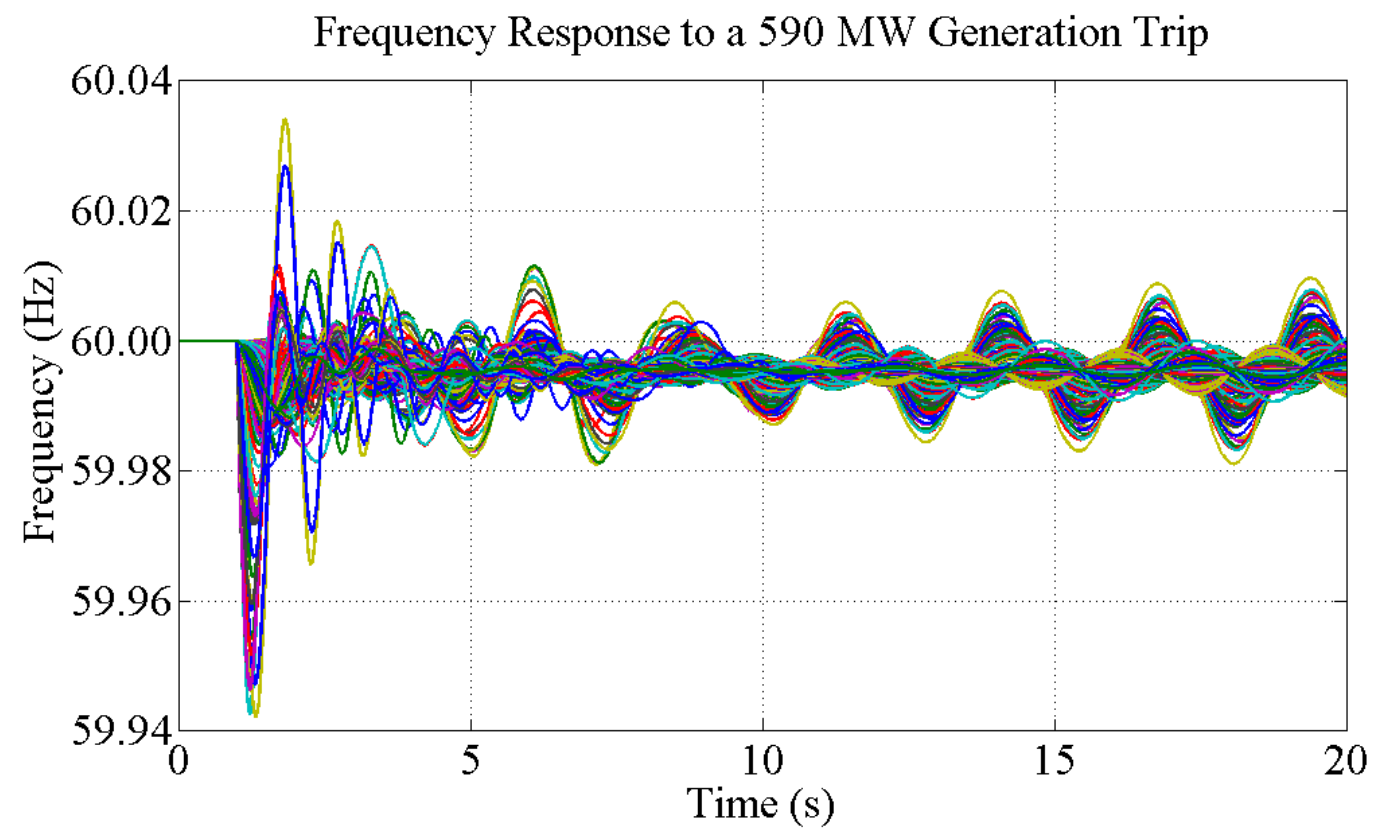

Figure 22. Frequency response with constant power load. 


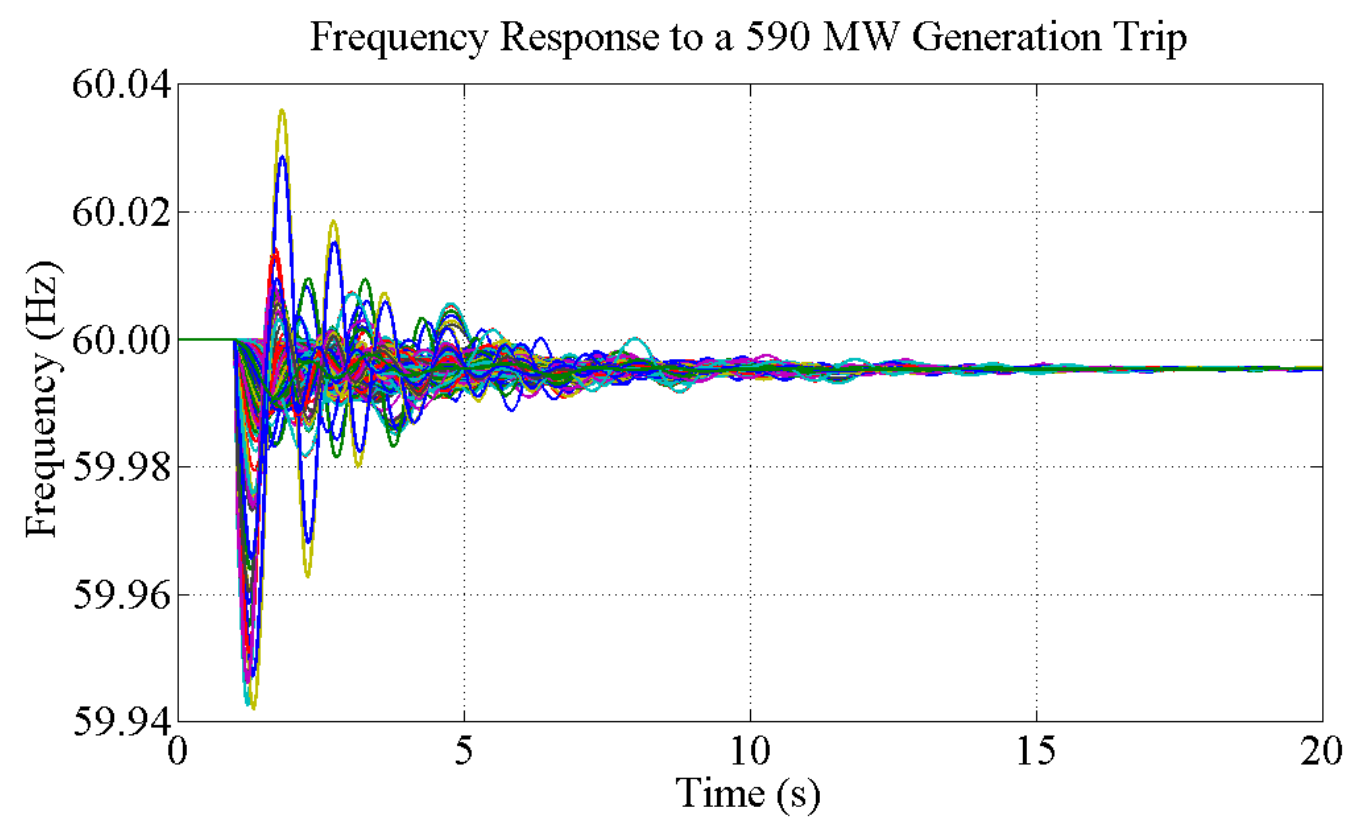

Figure 23. Frequency response with constant current/admittance load.

\subsection{FLAT RUN}

Numerical divergence is the enemy of smooth dynamic simulations. To ensure that the built case is not suffering from numerical issues and provides valid results, a 20-second no-disturbance simulation is performed on each case. As no disturbance applies, the system is supposed to stay static such that any variable is constant. However, if erroneous data exist and cause numerical issues, the system will drift from the steady state.

Figure 24 and 25 show a successful and unsuccessful flat run.

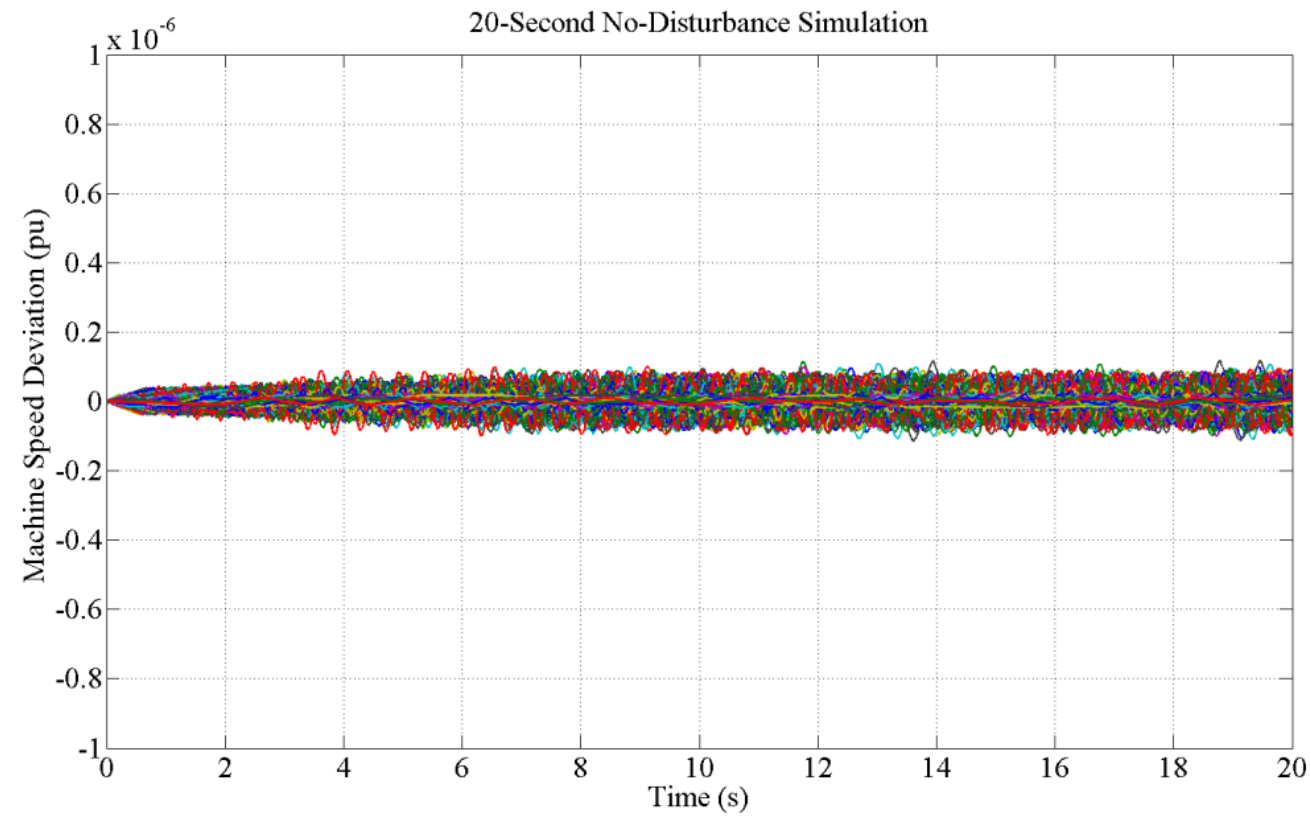

Figure 24. Successful 20-second flat run. 




Figure 25. Unsuccessful 20-second flat run.

\subsection{CASE STUDY}

To validate the 2030 EI dynamic model, frequency recordings by FNET/GridEye are used to adjust the inertia, percent of blocked governors, and load composite ratio. As the typical inertia value may drift from the real system, assumed inertia is adjusted uniformly so that the inter-area oscillation frequency matches. Governors are turned off starting from the largest thermal plant in order to match the settling frequency after generation trip and load shedding. The load composite ratio is adjusted accordingly to reflect the system damping.

Two tuned cases are shown in Figures 26 and 27. The first case is a 1300-MW generation trip at the McGuire Nuclear Station in North Carolina (NC). The second case is a 1400-MW generation trip at the Grand Gulf Nuclear Station in Mississippi (MS). The simulation results from the MMWG model, which is widely used by utility companies in the EI, are also plotted for comparison. The 2030 EI model more closely matches the measurement. 


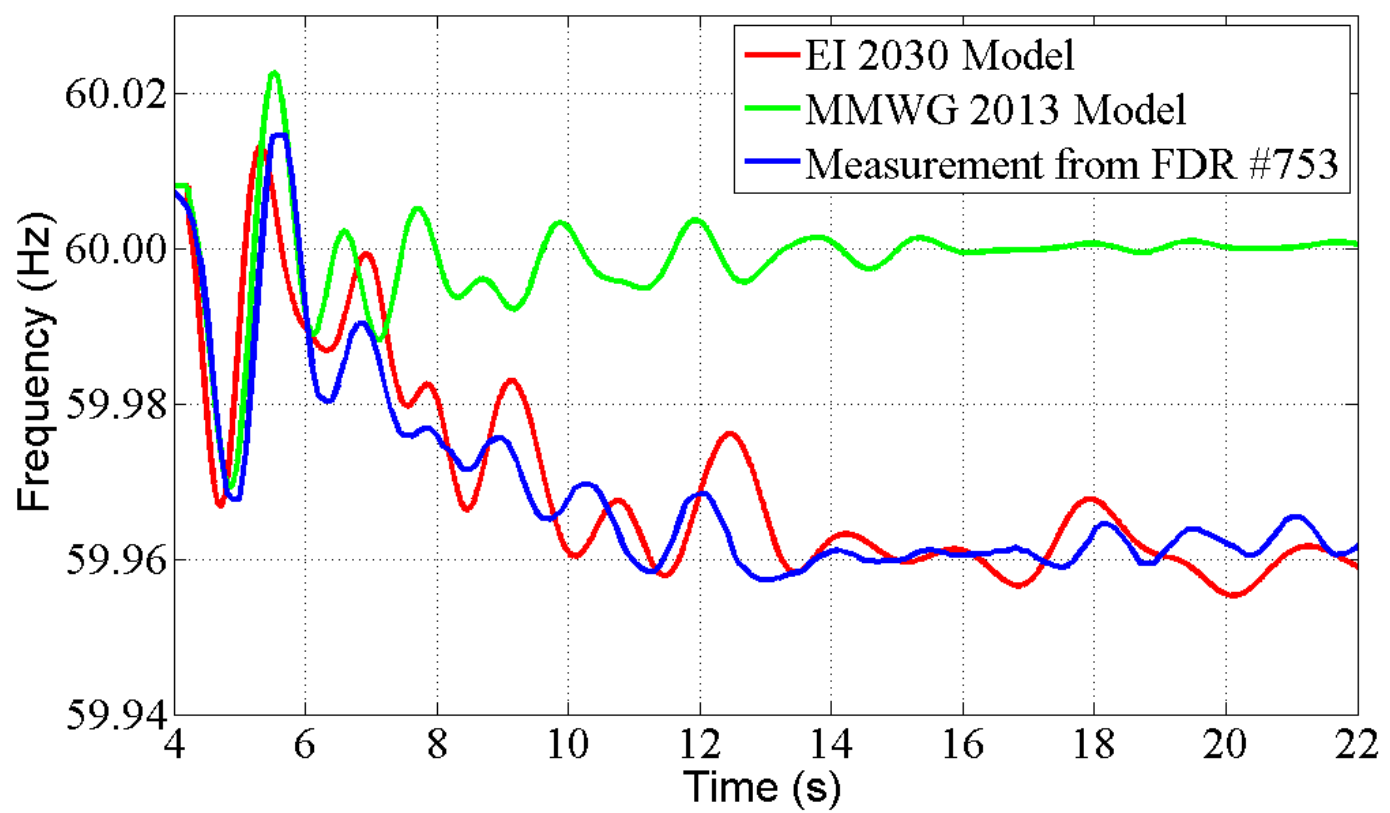

Figure 26. Frequency response of the generation trip in NC.

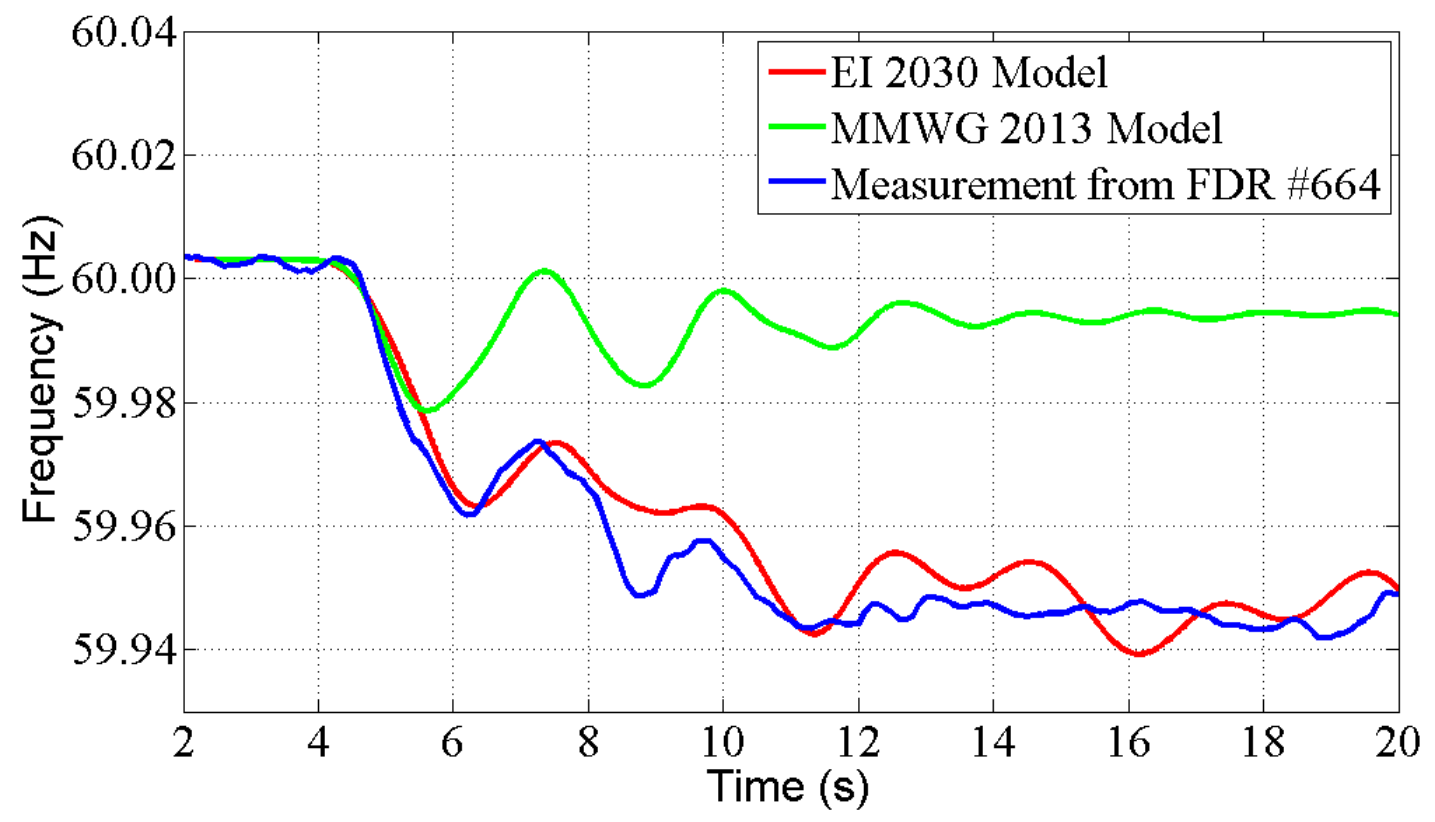

Figure 27. Frequency response of the generation trip in MS. 


\section{CONCLUSION AND DISCUSSION}

The 2030 EI dynamic model is developed based on the future power flow model constructed by the EIPC. A generic-parameter approach is demonstrated. The completed model is further refined by performing model validation through synchronized phasor measurement.

It is recognized that while the generic model is able to capture the major system dynamic characteristics, it may not match up perfectly at local areas. For this reason, ongoing efforts have been made to integrate real dynamic data with the model.

Using all three scenarios developed by the EIPC allows researchers to examine stability impacts under a wide variety of generation mixes, infrastructure build-outs, and load growth. Special attention will also be given to the impact of renewables and wide-area control strategies.

\section{REFERENCES}

1. Eastern Interconnection Planning Collaborative, Phase 1 Report: Formation of Stakeholder Process, Regional Plan Integration and Macroeconomic Analysis, December 2011 [Online], available: http://www.eipconline.com/uploads/Phase_1_Report_Final_12-23-2011.pdf.

2. $\quad$ Eastern Interconnection Planning Collaborative, Phase 2 Report: DOE Draft - Part 1 Interregional Transmission Development and Analysis for Three Stakeholder Selected Scenarios, December 2012 [Online], available:

http://eipconline.com/uploads/20130103_Phase2Report_Part1_Final.pdf.

3. Siemens Power Technologies International, PSS®E 33.1.1 Program Application Guide Volume 2, May 2012.

4. B. Stott, "Power system dynamic response calculations," in Proc.of the IEEE, vol. 67, no. 2, pp. 219-241, Feb. 1979.

5. P. Kundur, Power System Stability and Control, McGraw-Hill, New York, 1994.

6. P. M. Anderson and A. A. Fouad, Power System Control and Stability, Ames: The Iowa State University Press, 1977.

7. Y. Kazachkov and K. Patil, PSS®E Generic WT3 Wind Model User Guide, Siemens PTI, Schenectady, New York, July 2009.

8. Y. Kazachkov, R. Altman, J. Senthil, and K. Patil, PSS®E Wind Modeling Package for GE 1.5/1.6/2.5/2.75/4.0 MW Wind Turbines User Guide, Siemens PTI, Schenectady, New York, August 2011.

9. K. Clark, N. W. Miller, and J. J. Sanchez-Gasca, Modeling of GE Wind Turbine-Generators for Grid Studies, GE International, Schenectady, New York, April 2010.

10. IEEE Recommended Practice for Excitation System Models for Power System Stability Studies, IEEE Std. 421.5-1992, 1992.

11. I. C. Report, “Dynamic Models for Steam and Hydro Turbines in Power System Studies,” IEEE Trans. Power Apparatus and Systems, vol. PAS-92, no. 6, pp. 1904-1915, Nov. 1973.

12. R. P. Schulz, "Modeling of governing response in the Eastern Interconnection," in Proc. 1999 IEEE Power Engineering Society Winter Meeting, pp. 561-566. 
13. J. W. Ingleson and E. Allen, “Tracking the Eastern Interconnection frequency governing characteristic,” in Proc. 2010 IEEE Power and Energy Society General Meeting, pp. 1-6.

14. L. Pereira, J. Undrill, D. Kosterev, D.Davies, and S. Patterson, "A new thermal governor modeling approach in the WECC,” in Proc. 2003 IEEE Power Engineering Society General Meeting, pp. 819-829.

15. J. V. Milanovic, K. Yamashita, S. Martinez Villanueva, S. Z. Djokic, and L. M. Korunovic, "International Industry Practice on Power System Load Modeling," IEEE Trans. Power Systems, vol. 28, no. 3, pp. 3038-3046, Aug. 2013.

16. J. M. Undrill and T. F. Laskowski, "Model Selection and Data Assembly for Power System Simulations,” IEEE Trans. Power Apparatus and Systems, vol. PAS-101, no. 9, pp. 3333-3341, Sept. 1982.

17. System Dynamic Performance Subcommittee and Power System Engineering Committee, "Standard load models for power flow and dynamic performance simulation," IEEE Trans. Power Systems, vol. 10, no. 3, pp. 1302-1313, Aug. 1995.

18. T. V. Cutsem and C. Vournas, Voltage Stability of Electric Power Systems, Springer, 1998.

19. F. Milano, Power System Modeling and Scripting, Springer, 2010.

20. I. C. Decker, A. S. e Silva, R.J.G. da Silva, M. N. Agostini, N. Martins, and F. B. Prioste, "System wide model validation of the Brazilian Interconnected Power System,” in Proc. 2010 IEEE Power and Energy Society General Meeting, pp. 1-8.

21. D. N. Kosterev and D. Davies, "System model validation studies in WECC," in Proc. 2010 IEEE Power and Energy Society General Meeting, pp. 1-4.

22. Y. Liu, “A US-Wide Power Systems Frequency Monitoring Network,” in Proc. 2006 IEEE Power Systems Conference and Exposition, pp. 159-166.

23. L. Chen, P. N. Markham, and Y. Liu, "Wide-area dynamic model validation using FNET measurements,” in Proc. 2012 IEEE PES Innovative Smart Grid Technologies (ISGT),pp. 1-7.

24. L. Pereira, J. Undrill, D. N. Kosterev, D. Davies, and S. Patterson, “A new thermal governor modeling approach in the WECC,” IEEE Trans. Power Systems, vol. 18, no. 2, pp. 819-829, May 2003. 